\title{
The dual-field-of-view polarization lidar technique: a new concept in monitoring aerosol effects in liquid-water clouds - case studies
}

\author{
Cristofer Jimenez ${ }^{1}$, Albert Ansmann ${ }^{1}$, Ronny Engelmann ${ }^{1}$, David Donovan ${ }^{2}$, Aleksey Malinka ${ }^{3}$ Patric Seifert $^{1}$, \\ Robert Wiesen $^{1}$, Martin Radenz ${ }^{1}$, Zhenping Yin ${ }^{1,4,5}$, Johannes Bühl ${ }^{1}$, Jörg Schmidt ${ }^{6}$, Boris Barja ${ }^{7}$, and \\ Ulla Wandinger ${ }^{1}$ \\ ${ }^{1}$ Leibniz Institute for Tropospheric Research, Leipzig, Germany \\ ${ }^{2}$ Royal Netherlands Meteorological Institute (KNMI), De Bilt, the Netherlands \\ ${ }^{3}$ National Academy of Sciences of Belarus, Minsk, Belarus \\ ${ }^{4}$ School of Electronic Information, Wuhan University, Wuhan, China \\ ${ }^{5}$ Key Laboratory of Geospace Environment and Geodesy, Ministry of Education, Wuhan, China \\ ${ }^{6}$ Institute of Meteorology, University of Leipzig, Leipzig, Germany \\ ${ }^{7}$ Atmospheric Research Laboratory, University of Magallanes, Punta Arenas, Chile
}

Correspondence: Cristofer Jimenez (jimenez@ tropos.de)

Received: 19 May 2020 - Discussion started: 7 July 2020

Revised: 6 October 2020 - Accepted: 24 October 2020 - Published: 8 December 2020

\begin{abstract}
In a companion article (Jimenez et al., 2020), we introduced a new lidar method to derive microphysical properties of liquid-water clouds (cloud extinction coefficient, droplet effective radius, liquid-water content, cloud droplet number concentration $N_{\mathrm{d}}$ ) at a height of $50-100 \mathrm{~m}$ above the cloud base together with aerosol information (aerosol extinction coefficients, cloud condensation nuclei concentration $N_{\mathrm{CCN}}$ ) below the cloud layer so that detailed studies of the influence of given aerosol conditions on the evolution of liquid-water cloud layers with high temporal resolution solely based on lidar observations have become possible now. The novel cloud retrieval technique makes use of lidar observations of the volume linear depolarization ratio at two different receiver field of views (FOVs). In this article, Part 2, the new dual-FOV polarization lidar technique is applied to cloud measurements in pristine marine conditions at Punta Arenas in southern Chile. A multiwavelength polarization Raman lidar, upgraded by integrating a second polarization-sensitive channel to permit depolarization ratio observations at two FOVs, was used for these measurements at the southernmost tip of South America. Two case studies are presented to demonstrate the potential of the new lidar technique. Successful aerosol-cloud-interaction (ACI) studies based on measurements with the upgraded aerosol-cloud lidar in combination with a Doppler lidar of the vertical wind
\end{abstract}

component could be carried out with 1 min temporal resolution at these pristine conditions. In a stratocumulus layer at the top of the convective boundary layer, we found values of $N_{\mathrm{d}}$ and $N_{\mathrm{CCN}}$ (for $0.2 \%$ water supersaturation) ranging from $15-100$ and $75-200 \mathrm{~cm}^{-3}$, respectively, during updraft periods. The studies of the aerosol impact on cloud properties yielded ACI values close to 1 . The impact of aerosol water uptake on the ACI studies was analyzed with the result that the highest ACI values were obtained when considering aerosol proxies (light-extinction coefficient $\alpha_{\mathrm{par}}$ or $N_{\mathrm{CCN}}$ ) measured at heights about $500 \mathrm{~m}$ below the cloud base (and thus for dry aerosol conditions).

\section{Introduction}

Numerous details and aspects of aerosol-cloud interaction (ACI) are not well understood and thus not well considered and parameterized in weather and climate models. The reason for this gap in our knowledge is closely linked to the lack of adequate measurements, observational concepts, instrumentation, tools, and techniques for a detailed, continuous (camera-like) monitoring of cloud processes in a variety of aerosol environmental and meteorological conditions. Such continuous monitoring is only possible in well- 
designed ground-based remote sensing network structures. Network supersites, distributed around the world, preferably in hotspot regions of anthropogenic activities and climate change as well as in rural background regions, need to cover profiling of aerosol mixtures and their aerosol-type properties, cloud microphysical, optical, and cloud-type (phase) properties, and meteorological parameters such as temperature, relative humidity, and wind, especially of the vertical wind component and thus of updraft, downdraft, and wave characteristics. Aerosol influences on low-level liquid-water clouds over mixed-phase clouds to tropopause cirrus need to be monitored. Measurements of cloud-relevant aerosol parameters must even include heights within the lower stratosphere which may serve as a source for ice-nucleating particles of heterogeneous ice formation in high level cirrus layers. In Europe, ACTRIS (Aerosols, Clouds, and Trace gases Research InfraStructure; https://www.actris.eu/, last access: 2 December 2020) with its network structures Cloudnet (Illingworth et al., 2007) and EARLINET (European Aerosol Research Lidar Network) (Pappalardo et al., 2014) is responsible for the buildup of the necessary aerosol-cloud monitoring infrastructure.

There is still a strong request for the development of new and robust aerosol and cloud profiling techniques (Grosvenor et al., 2018). As a contribution to improved ACI field studies with a focus on liquid-water clouds, we offer a novel lidar measurement concept that permits continuous, vertically resolved observations of cloud-relevant aerosol properties below the cloud base, cloud microphysical properties in the lower part of the cloud layer, and the vertical wind component below and within the cloud parcels with a temporal resolution of 30-120 s. The methodological framework is presented in Part 1 (Jimenez et al., 2020). The selected measurement concept of combining aerosol lidar, cloud lidar, and wind Doppler lidar observations was already outlined and applied by Schmidt et al. (2014, 2015). However, a fast lidar technique for cloud observation (day and night and with updraft-resolving temporal resolution) was introduced only recently (Jimenez et al., 2017, 2018). In Part 1 (Jimenez et al., 2020), we presented the theoretical framework of the novel dual-field-of-view (dual-FOV) polarization lidar method, which allows us to derive microphysical properties of liquid-water clouds such as droplet number concentration $N_{\mathrm{d}}$, effective radius $R_{\mathrm{e}}$ of the droplets, and liquidwater content $w_{1}$ as well as the cloud extinction coefficient $\alpha$ in the cloud base region at 50 to $100 \mathrm{~m}$ above the cloud base. Together with the recently developed method to derive height profiles of cloud condensations nuclei (CCN) concentrations $\left(N_{\mathrm{CCN}}\right)$ from aerosol extinction coefficients $\alpha_{\mathrm{par}}$, measured with the same polarization lidar (Mamouri and Ansmann, 2016) below the cloud base, detailed studies of the impact of aerosol particles on the microphysical properties of droplets in the cloud base region of liquid-water cloud layers have become possible.
The instrumental setup can be easily integrated into existing ground-based aerosol and cloud remote sensing network supersites as already demonstrated in the case of the mobile ACTRIS Cloudnet station LACROS (Leipzig Aerosol and Cloud Remote Observation System; http://lacros.rsd.tropos. de/, last access: 2 December 2020), which is presently deployed for a long-term campaign in Punta Arenas, Chile, in the pristine marine environment of southernmost South America. Network observations of aerosol-cloud interaction on a continental scale offer new possibilities of co-operations between the measuring science community performing longterm observations of aerosols and clouds and the modeling community developing and improving atmospheric and Earth system models with the goal to better consider natural and anthropogenic aerosols and their impact on radiative transfer and cloud evolution in weather and climate forecast simulations. The models can be confronted with a continuous flow of aerosol and cloud observations for very different aerosol and meteorological conditions. This would probably lead to a significant step forward in the understanding of the role of aerosols in the atmospheric system. Furthermore, dual-FOV lidars can provide constraints for cloud radar retrievals (e.g., Frisch et al., 2002) so that full cloud profiling throughout cloud layers is possible. The new dual-FOV polarization lidar technique can be easily implemented in widespread aerosol polarization lidars (of, e.g., EARLINET) with near-range and far-range receiver telescopes, as will be discussed below, and can then contribute to the long-term monitoring of droplet microphysical properties in the lower part of liquid-water clouds within network structures.

In this second article (Part 2), we apply the new dual-FOV polarization lidar technique to recent aerosol and cloud observations at Punta Arenas, Chile, discuss the cloud retrieval uncertainties, compare the results with independent alternative cloud observations, and highlight the new potential of the lidar technique to significantly contribute to atmospheric and climate research in the field of ACI. Part 2 is organized as a stand-alone publication. Part 1 is therefore not needed as a prerequisite to follow the presentations and discussions in Part 2. In Sect. 2, we briefly summarize the data analysis procedure to retrieve the aerosol and cloud parameters for in-depth ACI studies as extensively discussed and explained in Part 1 (Jimenez et al., 2020). Sect. 3 provides details of the integration of the dual-FOV polarization lidar technique into a Polly (portable lidar system) instrument (Engelmann et al., 2016; Baars et al., 2016). The upgraded Polly is part of LACROS and consists of an aerosol-cloud lidar, a Doppler lidar for profiling of the vertical wind component, and a cloud radar as the main profiling instruments. LACROS was continuously operated at Punta Arenas, Chile, in the framework of the long-term field campaign DACAPOPESO (Dynamics, Aerosol, Cloud And Precipitation Observations in the Pristine Environment of the Southern Ocean; https://dacapo.tropos.de, last access: 2 December 2020) from November 2018 to the end of 2020. Details of the campaign 
and the goals of the investigations are outlined in Sect. 3.3. In the measurement section (Sect. 4), two case studies are presented. Case 1 (Sect. 4.1) is shown to discuss the basic and principle features of the new cloud retrieval technique. The potential of the new dual-FOV lidar to contribute to ACI research is then illuminated in Sect. 4.2 (case study 2). Concluding remarks and an outlook are given in Sect. 5.

\section{Data processing scheme}

As outlined in Part 1 (Jimenez et al., 2020), the basic motivation for the development of the dual-FOV polarization lidar technique was the need for simultaneous aerosol and cloud observations at day- and nighttime, with high temporal resolutions of the order of 30-120 s. The developed novel lidar method for liquid-water cloud observations is based on the measurement of the so-called volume linear depolarization ratio in the lower part of the water cloud at two different receiver FOVs. The required dual-FOV polarization lidar transmits linearly polarized laser pulses and detects the socalled cross- and co-polarized signal components. "Co" and "cross" denote the planes of polarization parallel and orthogonal to the plane of linear polarization of the transmitted laser pulses, respectively. The volume linear depolarization ratio is defined as the ratio of the cross- to the co-polarized signal and yields the basic information on the ratio of the cross- to the co-polarized backscatter coefficient. In water clouds, the depolarization ratio is sensitively influenced by multiple scattering and varies, e.g., with receiver FOV, cloud height, and cloud droplet number concentration and size of the droplets as explained in detail in Part 1. These relationships are used in the dual-FOV polarization lidar technique to retrieve the effective radius $R_{\mathrm{e}}$ of the droplets and the cloud extinction coefficient $\alpha$ in the cloud base region at 50 to $100 \mathrm{~m}$ above the cloud base by means of measured depolarization ratios at two FOVs, and, in the next step, to compute the liquid-water content $w_{1}$ and the cloud droplet number concentration $N_{\mathrm{d}}$ from the $R_{\mathrm{e}}$ and $\alpha$ values.

Table 1 provides an overview of all steps of the comprehensive analysis of cloud and aerosol data obtained with the new dual-FOV polarization lidar developed in Part 1 (Jimenez et al., 2020). The overall concept of lidar-based aerosol-cloud-interaction studies with a focus on liquidwater clouds is illustrated in Fig. 4 in Part 1. The dual-FOV polarization lidar technique allows us to derive simultaneously the microphysical properties of liquid-water clouds at a height of $z_{\text {ref }}=z_{\text {bot }}+75 \mathrm{~m}$ above the cloud base height $z_{\text {bot }}$ and the aerosol proxies $\alpha_{\mathrm{par}}$ and $N_{\mathrm{CCN}}$ at height $z_{\text {aer }}$ which can be freely selected and is typically about 250$750 \mathrm{~m}$ below the cloud base to avoid aerosol water-uptake effects (Skupin et al., 2016; Haarig et al., 2017) on the ACI studies.

In this article (Part 2), we apply the full methodology to a DACAPO-PESO measurement case collected at Punta Are- nas on 22 March 2019 and explain all retrieval steps listed in Table 1. The second case, measured on 23 February 2019, is then presented to highlight the new potential of this novel lidar approach to significantly improve ACI studies in the case of liquid-water clouds. Before that, we describe the lidar hardware needed for such observations and the way to obtain the required depolarization ratios from the measured lidar signals that serve as the basic input in the cloud data analysis scheme.

\section{Instrument and experiment}

\subsection{Polly with dual-FOV capability}

We implemented the dual-FOV polarization lidar technique in several lidars of the Leibniz Institute for Tropospheric Research (TROPOS) during recent years. The dual-FOV polarization lidar technique was firstly integrated into the EARLINET (European Aerosol Research Lidar Network) lidar MARTHA (Multiwavelength Atmospheric Raman lidar for Temperature, Humidity, and Aerosol profiling) (Jimenez et al., 2019). MARTHA was already equipped with the dualFOV Raman lidar technique (Schmidt et al., 2013, 2014), so direct comparisons of cloud observations with the Raman lidar and the polarization lidar method were possible. We found in general good agreement in the retrieval of cloud optical and microphysical properties (Jimenez et al., 2017, 2018). Encouraged by this successful comparison, we stepped forward and equipped four Polly (portable lidar system) instruments (Engelmann et al., 2016) with the new dual-FOV polarization lidar technique. These four lidar systems are and were involved in several long-term field activities at very different aerosol and environmental conditions, namely at Dushanbe, Tajikistan, in Central Asia (continuous measurements since June 2019), aboard the German ice breaker Polarstern (North Pole, a 1-year campaign from October 2019 to September 2020), at Punta Arenas (a 2-year campaign from November 2018 to the end of 2020), and at Limassol, Cyprus (continuous measurements since October 2020). Aerosol retrieval methods and measurement examples can be found in Baars et al. (2016) and Hofer et al. (2017, 2020). Improved water vapor observations (water vapor mixing ration, relative humidity) by combining lidar and regular photometer observations were recently discussed by Dai et al. (2018). In this section, we concentrate on the new approach of cloud measurements at two FOVs.

Figure 1 shows the transmitter and receiver configuration of the Polly instrument of the Punta Arenas remote sensing facility. The lidar is described in detail by Engelmann et al. (2016) and Hofer et al. (2017). Laser beam diameter and divergence are $45 \mathrm{~mm}$ and $0.2 \mathrm{mrad}$, respectively, after beam expansion. The polarization impurity (fraction of nonlinear polarized light) of the transmitted laser beam is less than $0.1 \%$. The receiver unit consists of the near-range re- 
Table 1. Overview of the cloud and aerosol retrieval procedure (step-by-step data analysis). The retrieval procedure starts with the determination of the cloud base height $z_{\text {bot }}$. The cloud depolarization ratios $\bar{\delta}_{\text {in }}$ and $\bar{\delta}_{\text {out }}$ and the ratio $\bar{\delta}_{\text {rat }}=\bar{\delta}_{\text {in }} / \bar{\delta}_{\text {out }}$, integrated over the height range from the cloud base at $z_{\text {top }}$ to the cloud retrieval or reference height $z_{\text {ref }}$, are calculated from the height profiles of measured volume linear depolarization ratios (see Sect. 3.2). The cloud products $R_{\mathrm{e}}, \alpha, w_{1}$, and $N_{\mathrm{d}}$ are given for the reference height $z_{\text {ref }}, 75 \mathrm{~m}$ above the cloud base height $z_{\text {bot }}$. The computation of the aerosol-cloud-interaction (ACI) efficiencies $E_{\mathrm{ACI}}$ is based on $N_{\mathrm{d}}$, particle extinction coefficient $\alpha_{\text {par }}$, and CCN concentration $N_{\mathrm{CCN}}$ at $z$ aer, usually several hundreds of meters below the cloud base. The aerosol proxies are determined from aerosol measurements with the same dual-FOV lidar. All equations refer to Part 1 (Jimenez et al., 2020).

\begin{tabular}{|c|c|c|c|}
\hline Parameter & Symbol & Equation & Uncertainty \\
\hline Cloud base height & $z_{\text {bot }}$ & & $0.1 \%-1 \%$ \\
\hline \multirow[t]{3}{*}{ Cloud depolarization ratios } & $\bar{\delta}_{\text {in }}\left(z_{\text {bot }}, z_{\text {ref }}\right)$ & Eq. (23) & $5 \%$ \\
\hline & $\bar{\delta}_{\text {out }}\left(z_{\text {bot }}, z_{\text {ref }}\right)$ & Eq. (24) & $5 \%$ \\
\hline & $\bar{\delta}_{\text {rat }}\left(z_{\text {bot }}, z_{\text {ref }}\right)$ & Eq. (25) & $10 \%-15 \%$ \\
\hline Droplet effective radius & $R_{\mathrm{e}}\left(z_{\mathrm{ref}}\right)$ & Eq. (26) & $15 \%$ \\
\hline Cloud extinction coefficient & $\alpha\left(z_{\text {ref }}\right)$ & Eq. (27) & $15 \%-20 \%$ \\
\hline Liquid-water content & $w_{1}\left(z_{\text {ref }}\right)$ & Eq. (4) & $25 \%$ \\
\hline Cloud droplet number concentration & $N_{\mathrm{d}}\left(z_{\text {ref }}\right)$ & Eq. (6) & $25 \%-75 \%$ \\
\hline Aerosol depolarization ratio & $\delta_{\mathrm{par}}(z)$ & & $5 \%-10 \%$ \\
\hline Aerosol extinction coefficient & $\alpha_{\mathrm{par}}\left(z_{\mathrm{aer}}\right)$ & & $20 \%$ \\
\hline Cloud condensation nuclei concentration & $N_{\mathrm{CCN}}\left(z_{\mathrm{aer}}\right)$ & Eqs. (36)-(38) & $30 \%-100 \%$ \\
\hline Aerosol-cloud-interaction efficiency & $E_{\mathrm{ACI}, \alpha_{\mathrm{par}}}\left(N_{\mathrm{d}}, \alpha_{\mathrm{par}}\right)$ & Eq. (39) & \\
\hline Aerosol-cloud-interaction efficiency & $E_{\mathrm{ACI}, \mathrm{N}_{\mathrm{CCN}}}\left(N_{\mathrm{d}}, N_{\mathrm{CCN}}\right)$ & Eq. (40) & \\
\hline
\end{tabular}

ceiver part (purple frame in Fig. 1), optimized to deliver particle backscatter and extinction profiles almost down to the ground determined from measured total and nitrogen Raman backscatter signals at $355,387,532$, and $607 \mathrm{~nm}$, and a farrange receiver part (blue frame). The diameter of the primary mirror of the far-range Newtonian telescope is $30 \mathrm{~cm}$. The overlap of the laser beam with the receiver FOV is incomplete for heights below about $800 \mathrm{~m}$ above ground level (a.g.1.) and allows for accurate aerosol and cloud profiling for heights above about $400 \mathrm{~m}$ a.g.l. only (after the correction of the overlap effects). For the far-range channels, the selected $\mathrm{FOV}_{\text {in }}$ is $1.0 \mathrm{mrad}$. The FOV for the near-range channels is $\mathrm{FOV}_{\text {out }}=2.0 \mathrm{mrad}$. As can be seen in contrast to a classical polarization lidar as described above, the Polly instrument measures the cross-polarized and the total (co- plus crosspolarized) signal components with the far-range telescope. The reasons for this specific design are explained below.

The near-range receiver part was not designed for polarization-sensitive lidar return observations. A $50 \mathrm{~mm}$ fiber-wired telescope collects the total (co- plus crosspolarized) backscatter signals. To realize the dual-FOV polarization lidar technique, we installed another receiver unit (with $50 \mathrm{~mm}$ telescope) that permits measurements of the cross-polarized signal at $532 \mathrm{~nm}$ at $\mathrm{FOV}_{\text {out }}=2.0 \mathrm{mrad}$ (top part, purple frame, in Fig. 1). The details of the optical elements and the design of this cross-polarized channel are described by Jimenez et al. (2019). Only a polarizer and a collimation lens are used to collect the backscattered crosspolarized laser photons which are then counted by a photomultiplier tube.

\subsection{Determination of calibrated depolarization ratios at two FOVs}

As mentioned, all Polly instruments measure the crosspolarized and the total (co- plus cross-polarized) signal components. The co-polarized signal component is not recorded. The measurement of the total backscatter coefficient facilitates the determination of the particle backscatter coefficient and, more importantly, guarantees a direct observation of the extinction-to-backscatter ratio without introducing uncertainties by composing the total backscatter signal from the two (cross and co-polarized) signal components, measured with different receiver channel efficiencies which need to be measured on a regular basis. To be widely in line with the notation in Engelmann et al. (2016), we switch from indices $\perp, \|$, and $\perp+\|$ (for the total backscatter signal) to c (cross), $\mathrm{p}$ (parallel), and $\mathrm{t}$ (total), respectively. Because of measuring the cross-polarized and total backscatter signal components, we introduce

$\delta^{\prime}(z)=\frac{S_{\mathrm{c}}(z)}{S_{\mathrm{t}}(z)}$

to distinguish this signal ratio from the volume depolarization ratio as defined by Eq. (8) in Part 1. According to Engelmann et al. (2016), the volume depolarization ratio is given by

$\delta(z)=\frac{1-\delta^{\prime}(z) / C}{\delta^{\prime}(z) F_{\mathrm{t}} / C-F_{\mathrm{c}}}$,

with the transmission ratio $F$ and the absolute calibration parameter $C$ (explained below). The transmission ratio $F$ is de- 


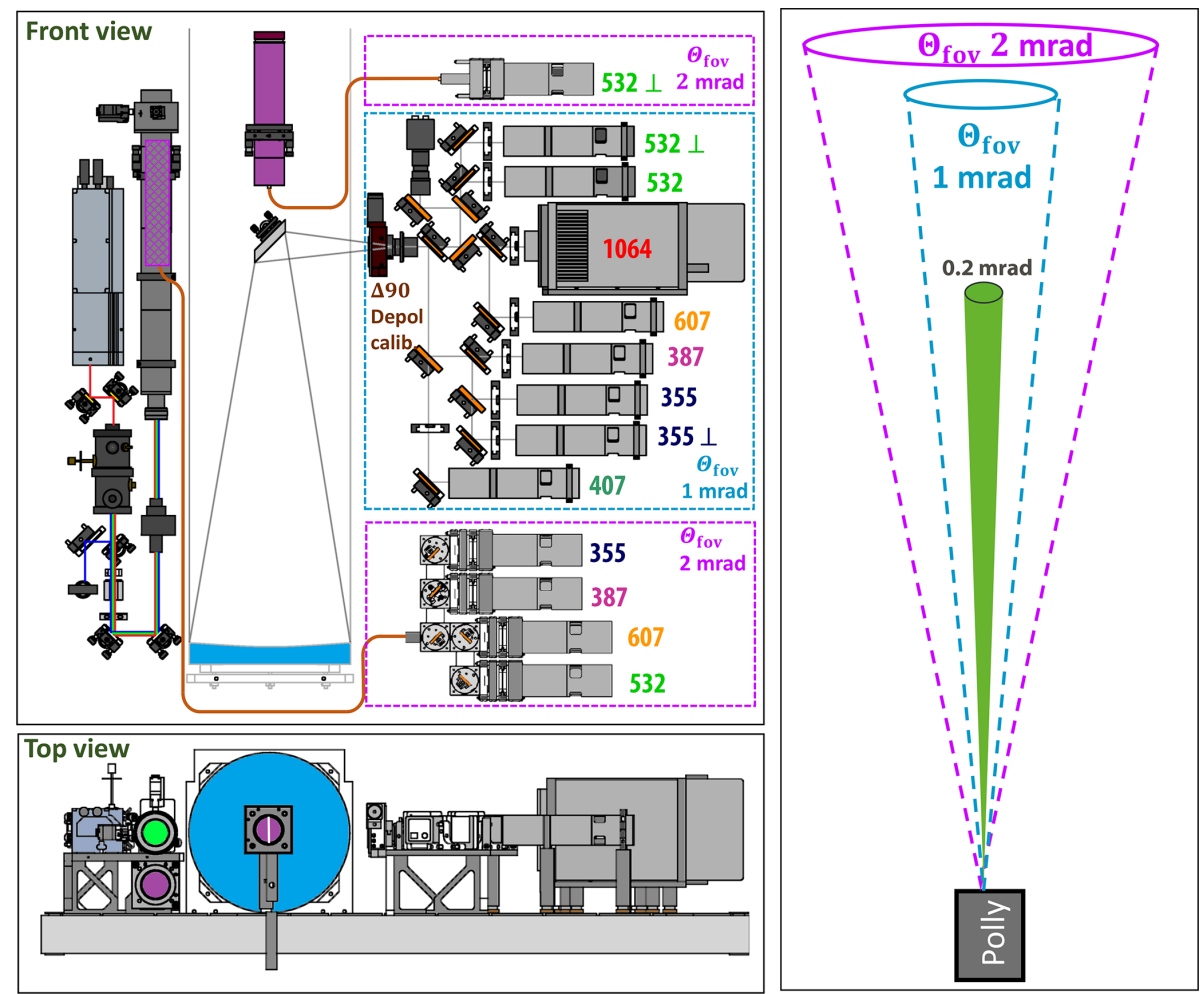

Figure 1. Optical setup of the Polly lidar (left side, same as in Fig. 3 of Engelmann et al., 2016). The upper left part displays the front view of the system, the lower left part a top view. The transmitter unit is mounted to the left of the main lidar telescope (in blue). Laser light transmission is indicated by a green circle in the top-view sketch. Backscattered light is collected with a Newtonian telescope (blue area in the top-view sketch, FOV $=1 \mathrm{mrad}$, far-range telescope) and then passed towards the far-range receiver unit to the right. All optical elements and detector channels belonging to the $1 \mathrm{mrad}$ FOV receiver block are given in a blue frame. The numbers indicate the wavelength in nanometers of the detection channels, and $\perp$ denotes the cross-polarized channels. A polarizer is mounted in front of the pinhole (entrance of the farrange receiver unit) and used for the absolute calibration of the depolarization measurements at 1 mrad FOV (for details, see Engelmann et al., 2016). The purple parts and the purple frame (top view, front view sketch) belong to the 2 mrad FOV receiver unit (near-range receiver unit). An additional $5 \mathrm{~cm}$ receiver telescope (purple; for details, see Jimenez et al., 2019) is mounted above the secondary mirror of the far-range telescope and collects the cross-polarized signal component at FOV $=2 \mathrm{mrad}$. To the right of the optical setup, the dual-FOV polarization lidar geometrical configuration is illustrated, sketching the footprints of the laser beam and FOVs with height.

fined as

$F_{i}=\frac{\eta_{i, \mathrm{c}}}{\eta_{i, \mathrm{p}}}$

with channels $i=\mathrm{c}$ (cross-polarized signal) and $i=\mathrm{t}$ (total backscatter signal). As mentioned, the index $p$ indicates here the plane of laser polarization (parallel-polarized signal channel). $F_{i}$ describes the ratio of transmission $\eta$ for crosspolarized light to the transmission for co-polarized light for channel $i$. For the Polly system at Punta Arenas (used here), the $F_{i}$ values were determined from measurements with an artificial light source with a polarizer mounted in front of each channel (Mattis et al., 2009). The values are $F_{\mathrm{t}}=1.09$ and $F_{\mathrm{c}}=800$ for the far-range channels $\left(\mathrm{FOV}_{\text {in }}\right)$ and $F_{\mathrm{t}}=1$ and $F_{\mathrm{c}}=500$ for the near-range channels $\left(\mathrm{FOV}_{\text {out }}\right)$.

The absolute calibration parameter $C$ in Eq. (2) is defined as

$C=\frac{1+F_{\mathrm{t}}}{1+F_{\mathrm{c}}} \sqrt{\delta^{\prime}(z) 45^{\circ} \delta^{\prime}(z)-45^{\circ}}$ and obtained from regular and automated clear-sky measurements. The so-called $\Delta 90^{\circ}$ calibration method (formerly known as $\pm \Delta 45^{\circ}$ calibration) (Freudenthaler et al., 2009; Freudenthaler, 2016; Engelmann et al., 2016) is applied to obtain highly accurate depolarization ratio observations for the $\mathrm{FOV}_{\text {in }}$ channels (far-range receiver). In order to include this method in the automated measurement procedure of Polly, a remote-controlled rotary mount with a socalled sheet polarizer close to the focal plane of the receiver telescope was added to the system. This sheet polarizer is equipped with an off-center hole to measure without the polarizer into the light path in normal mode by rotating the hole onto the optical axis. Three times per day, the polarizer is rotated automatically by -45 and $45^{\circ}$ with respect to the laser polarization plane in the light path for calibration to determine the signal ratios $\delta^{\prime}(z)_{-45^{\circ}}$ and $\delta^{\prime}(z)_{45^{\circ}}$. The resulting profile of $C$ slightly varies with height because of signal noise and slightly different conditions during the measure- 
ment periods with -45 and $45^{\circ}$ polarization. Thus, the most favorable conditions are cloud-free, clear-sky periods for the measurement of $C$. In practice, profile values over several kilometers in the vertical column are averaged to reduce the impact of signal noise on $C$.

The uncertainties in the measurements and data analysis in obtaining the volume depolarization ratio are caused, e.g., by the influence of laser linear polarization purity and uncertainties in the determination of the transmission ratios $F_{i}$ and the procedure to obtain the absolute calibration constant $C$. The uncertainties are discussed by Engelmann et al. (2016) and Belegante et al. (2018).

In our approach of a dual-FOV polarization lidar, we have to distinguish between measurements with $\mathrm{FOV}_{\text {in }}$ and $\mathrm{FOV}_{\text {out }}$. Above, we described the retrieval of the volume depolarization ratio for $\mathrm{FOV}_{\text {in }}$. To indicate this we specify $C=C_{\text {in }}, \delta=\delta_{\text {in }}$, and $F_{i}=F_{i, \text { in }}$. As in the case of $F_{i}=F_{i, \text { in }}$, we can obtain $F_{i, \text { out }}$ for $\mathrm{FOV}_{\text {out }}$ as well.

The calibration constant $C_{\text {out }}$ cannot be measured with the rotating polarizer. $C_{\text {out }}$ is obtained under the assumption that the volume depolarization ratios for $\mathrm{FOV}_{\text {in }}$ and $\mathrm{FOV}_{\text {out }}$ are equal under clear-sky conditions (i.e., in the absence of any cloud layer and related multiple scattering effects). It can be shown that for $\delta_{\text {out }}(z)=\delta_{\text {in }}(z)$,

$C_{\text {out }}=\delta_{\text {out }}^{\prime}(z)\left(\frac{1+F_{\mathrm{t}, \text { out }} \delta_{\text {in }}(z)}{1+F_{\mathrm{c}, \text { out }} \delta_{\text {in }}(z)}\right)$.

After careful determination of the $F_{i}$ and $C$ values for $\mathrm{FOV}_{\text {in }}$ and $\mathrm{FOV}_{\text {out }}$ we can now proceed to analyze cloud observations, as described in Sect. 4 in Part 1 (Jimenez et al., 2020).

The cloud-integrated volume depolarization ratio for $\mathrm{FOV}_{\text {in }}$ signals as defined by Eq. (23) in Part 1 is now given by

$\bar{\delta}_{\text {in }}\left(z_{\text {bot }}, z_{\text {ref }}\right)=\frac{1-\bar{\delta}_{\text {in }}^{\prime} / C_{\text {in }}}{\bar{\delta}_{\text {in }}^{\prime} F_{\text {t,in }} / C_{\text {in }}-F_{\mathrm{c}, \text { in }}}$,

with $\bar{\delta}_{\text {in }}^{\prime}$ calculated from the cross-polarized and the total signal components:

$\bar{\delta}_{\text {in }}^{\prime}=\frac{\int_{z_{\text {bot }}}^{z_{\text {ref }}} S_{\mathrm{c}, \text { in }}(z) \mathrm{d} z}{\int_{z_{\text {bot }}}^{z_{\text {ref }}} S_{\mathrm{t}, \text { in }}(z) \mathrm{d} z}$.

For FOV ${ }_{\text {out }}$, we obtain correspondingly

$\bar{\delta}_{\text {out }}\left(z_{\text {bot }}, z_{\text {ref }}\right)=\frac{1-\bar{\delta}_{\text {out }}^{\prime} / C_{\text {out }}}{\bar{\delta}_{\text {out }}^{\prime} F_{\mathrm{t}, \text { out }} / C_{\text {out }}-F_{\mathrm{c}, \text { out }}}$,

with $\bar{\delta}_{\text {out }}^{\prime}$ calculated from the cross-polarized and the total signal components:

$\bar{\delta}_{\text {out }}^{\prime}=\frac{\int_{z_{\text {bot }}}^{z_{\text {ref }}} S_{\mathrm{c}, \text { out }}(z) \mathrm{d} z}{\int_{z_{\text {bot }}}^{z_{\text {ref }}} S_{\mathrm{t}, \text { out }}(z) \mathrm{d} z}$.
The cloud-integrated depolarization ratios $\bar{\delta}_{\text {in }}\left(z_{\text {bot }}, z_{\text {ref }}\right)$ and $\bar{\delta}_{\text {out }}\left(z_{\text {bot }}, z_{\text {ref }}\right)$ and the ratio $\bar{\delta}_{\text {rat }}=\bar{\delta}_{\text {in }} / \bar{\delta}_{\text {out }}$ as defined by Eqs. (23)-(25) in Part 1 are the input in the retrieval of cloud microphysical properties as described in Sect. 4 in Part 1 and summarized in Table 1.

\subsection{DACAPO-PESO and LACROS}

The lidar observations at Punta Arenas $\left(53.2^{\circ} \mathrm{S}, 70.9^{\circ} \mathrm{W}, 9 \mathrm{~m}\right.$ above sea level, a.s.1.), Chile, were conducted in the framework of the DACAPO-PESO campaign from November 2018 to the end of 2020. DACAPO-PESO belongs to a series of long-term ACI-related field studies performed with the mobile LACROS station. Before that, we deployed LACROS for the 17-month field campaign CyCARE (Cyprus Clouds, Aerosol and Rain Experiment) at Limassol, Cyprus (October 2016 to March 2018) (Bühl et al., 2019; Ansmann et al., 2019), in the highly polluted and dusty eastern Mediterranean. All these campaigns are aimed at the central question: how do aerosol particles influence the evolution and microphysical properties of liquid-water, mixed-phase, and ice clouds and precipitation in different meteorological regimes and at contrasting levels of anthropogenic and natural aerosol concentrations? The novel dual-FOV polarization lidar fills an important gap and covers the ACI research in the case of liquid-water clouds.

We upgraded meanwhile several Polly instruments to dualFOV polarization lidars. Besides the lidar at Punta Arenas, another upgraded dual-FOV Polly was operated at the North Pole (aboard the German ice breaker Polarstern in the framework of the MOSAiC campaign (September 2019-September 2020). MOSAiC (Multidisciplinary Drifting Observatory for the Study of Arctic Climate; https:// mosaic-expedition.org, last access: 2 December 2020) is the largest Arctic field campaign ever realized. A new Polly, designed as dual-FOV polarization lidar from the beginning, is now operated at Dushanbe, Tajikistan, in a dusty and polluted region of Central Asia in the framework of a longterm (unlimited) CADEX follow-up campaign (since June 2019). CADEX (Central Asian Dust Experiment) (Hofer et al., 2017, 2020) was conducted from March 2015 to August 2016. In the framework of the 7-year project EXCELSIOR (EXcellence Research Center for Earth SurveiLlance and Space-Based MonItoring Of the EnviRonment; https://excelsior2020.eu/the-project/, last access: 2 December 2020), we deployed a new dual-FOV Polly, integrated into the new EXCELSIOR supersite at Limassol, in October 2020. Finally, the fourth new dual-FOV Polly will be set up at Cabo Verde (in the summer of 2021) in the outflow regime of African dust and biomass burning smoke, as part of ACTRIS.

The mobile Leipzig Cloudnet supersite LACROS (Bühl et al., 2013, 2016; Ansmann et al., 2019) was run continuously at the University of Magallanes (UMAG) at Punta Arenas and covered two summer and winter seasons of aerosol 
and cloud observations during the DACAPO-PESO campaign. LACROS is equipped with the dual-FOV polarization lidar, a wind Doppler lidar, $35 \mathrm{GHz}$ Doppler cloud radar, ceilometer, disdrometer, and microwave radiometer. In addition, an Aerosol Robotic Network (AERONET) sun photometer (AERONET, 2020; Holben et al., 1998) was operated.

\section{Measurements}

We discuss two measurement cases of the DACAPO-PESO campaign. The first case study (22 March 2019) deals with the development of an extended altocumulus field in the pristine free troposphere over Punta Arenas, Chile, during the autumn season. The full aerosol and cloud data analysis scheme is applied, the uncertainties in the cloud products obtained with the dual-FOV lidar are discussed, and the basic results (cloud extinction coefficient, effective radius) are compared with alternative independent retrievals. On 23 February 2019 (case 2), a long-lasting evolution of a stratocumulus deck at the top of the convective summertime boundary layer was observed. This case is used to illuminate the full potential of a dual-FOV polarization lidar regarding ACI studies in the case of liquid-water clouds.

\subsection{Case study of 22 March 2019}

Figure 2 provides an overview of the cloud conditions over Punta Arenas on 22 March 2019. The narrow FOV signal channels of the Polly lidar are used here. A complex layering of low-level liquid-water clouds, mid-level mixed-phase and upper tropospheric ice clouds was found on this autumn day. In Fig. 2a, optically thin, transparent ice clouds prevailed at heights above about $5 \mathrm{~km}$, whereas optically thick liquid and mixed-phase clouds, indicated by dark blue columns above the clouds in Fig. 2a, dominated at heights below $4 \mathrm{~km}$. The depolarization ratio was high with values of about 0.4 in the ice clouds caused by strong light depolarization by hexagonal ice crystals. Cloud droplets dominate light depolarization in the liquid-water clouds at heights below $4 \mathrm{~km}$. The depolarization ratio monotonically increase from values around zero (for ideal spheres) to values around $0.15-0.2$ caused by strong multiple scattering by water droplets. It should be mentioned that all POLLY instruments are tilted to an offzenith angle of $5^{\circ}$ to avoid a strong impact of specular reflection by falling, horizontally aligned ice crystals which lead to rather low depolarization ratios and, in this way, considerably disturb cloud observations and the separation of liquid-water, mixed-phase, and ice cloud layers.

The results of the Cloudnet classification (Cloudnet, 2020) in Fig. 3a are in good agreement with Fig. 2. The Cloudnet identification and classification method is based on cloud radar, microwave radiometer, and ceilometer observations (Illingworth et al., 2007; Bühl et al., 2016; Baars et al.,
2017). According to the Cloudnet classification, the clouds below $3.5 \mathrm{~km}$ height were mostly liquid-water clouds (blue layers), partly mixed-phase clouds in the height range from 4-6 km, and pure ice clouds (yellow layers) higher up. The 0 and $-10^{\circ} \mathrm{C}$ temperature levels were observed at about 2 and $3.5 \mathrm{~km}$ height according to the radiosonde launched at Punta Arenas on 22 March 2019, 12:00 UTC. Some artifacts are visible. For example, the detection of ice crystals in the liquid layers at $3-3.5 \mathrm{~km}$ around 06:00 UTC and after 09:00 UTC is wrong and caused by missing ceilometer observations. The ceilometer laser beam could not penetrate the lower, optically dense cloud layer around 06:00 UTC.

Figure $3 \mathrm{~b}$ shows the respective dual-FOV polarization lidar observations. These measurements widely confirm the Cloudnet classification results. The observations are shown in terms of the ratio $\delta_{\text {rat }}=\delta_{\text {in }} / \delta_{\text {out }}$ with $\mathrm{FOV}_{\text {in }}=1 \mathrm{mrad}$ and $\mathrm{FOV}_{\text {out }}=2 \mathrm{mrad}$. It can be seen that the upper layers contained ice crystals which produce a strong, rather narrow, and non-depolarizing forward scattering peak so that both FOVs measure the same backscattering and depolarization features; therefore, $\delta_{\text {rat }}$ was mostly close to 1.0 (reddish colors). In contrast, $\delta_{\text {rat }}$ was clearly $<1.0$ in the shallow altocumulus layers between 3 and $3.5 \mathrm{~km}$ height (yellow and green color) caused by a larger contribution to the depolarization ratio by droplet multiple scattering in the case of the larger receiver $\mathrm{FOV}_{\text {out }}=2 \mathrm{mrad}$. Even the presence of drizzle droplets at $1.5 \mathrm{~km}$ is detected in Fig. 2b. These large droplets cause $\delta_{\text {rat }}$ values close to 1 because of a narrow forward scattering peak and similar multiple scattering effects in both FOVs.

In the following, we concentrate on the liquid-water cloud layer from 3-3.5 km height observed over several hours from about 04:30 UTC (01:30 local time) to 11:00 UTC (08:00 local time). The results of the dual-FOV polarization lidar measurements are shown in Fig. 4. The data analysis procedure was as follows: in the first step, the background and rangecorrected total backscatter signals, available with $30 \mathrm{~s}$ temporal resolution, were used to obtain the information about the cloud base height $z_{\text {bot. }}$. These signals were normalized to the maximum signal value $P_{\text {norm }}(z)$ of the total backscatter profile (in the lower part of the cloud layer). A threshold $P_{\text {norm }}(z)>0.06$ was set to estimate the cloud base height within the signal profile segment from below the cloud base up to about $100 \mathrm{~m}$ within the cloud layer. To avoid the influence of signal noise in the cloud base calculation, a smoothing over five height bins $(37.5 \mathrm{~m})$ was applied to the $30 \mathrm{~s}$ profiles. This smoothing was only performed for the determination of $z_{\text {bot }}$. The approach is similar to the method of Donovan et al. (2015) to determine $z_{\text {bot }}$ of liquid-water clouds. The time series of the estimated cloud base height is shown in Fig. 4a.

In the next step, the cross-polarized and total signal components from the cloud base to $75 \mathrm{~m}$ (10 range or height bins) above the cloud base were averaged. A temporal resolution of $2 \mathrm{~min}$ was selected (Fig. 4). The integrated depolarization ratios $\bar{\delta}_{\text {in }}$ and $\bar{\delta}_{\text {out }}$ were calculated by using Eqs. (6)-(8) (in 


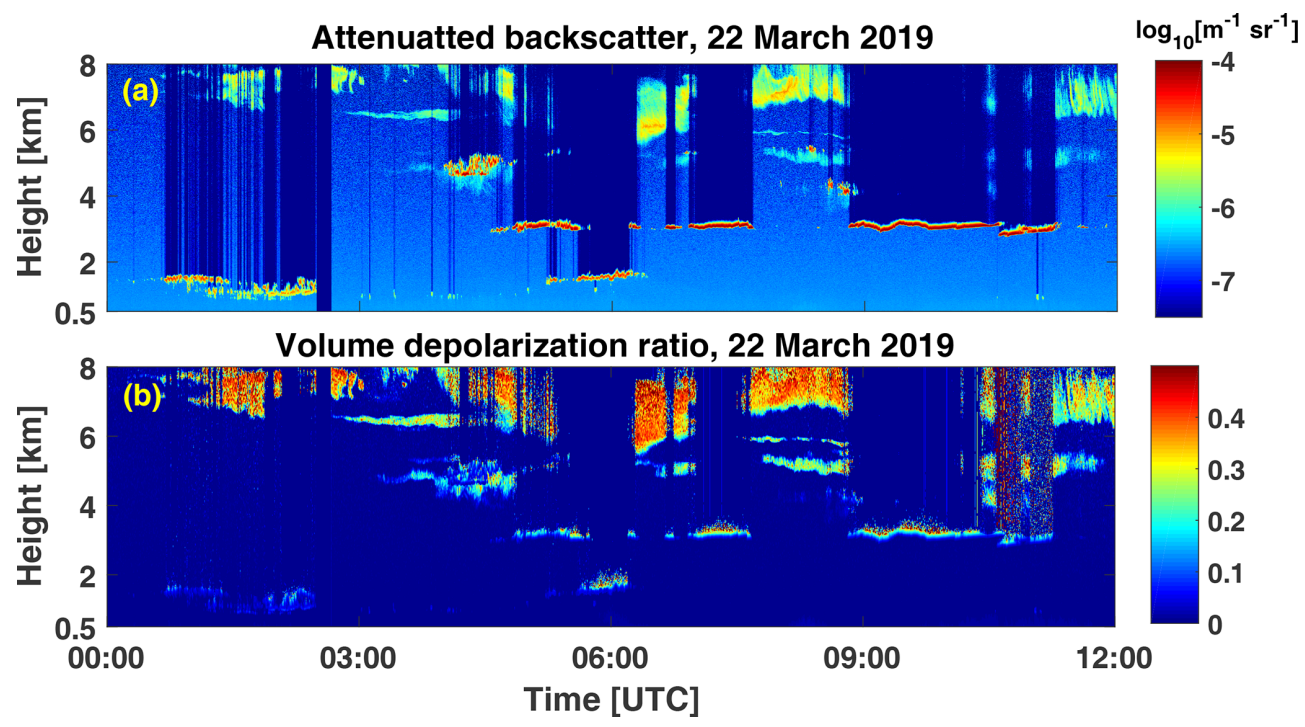

Figure 2. Liquid-water cloud layers at heights $<3.5 \mathrm{~km}$ and ice-containing clouds between 4 and $8 \mathrm{~km}$ height in the pristine marine atmosphere over Punta Arenas observed with polarization lidar on 22 March 2019. Height-time display of (a) attenuated backscatter at 1064 nm and (b) volume linear depolarization ratio at $532 \mathrm{~nm}$ measured with $30 \mathrm{~s}$ temporal and $7.5 \mathrm{~m}$ vertical resolution are presented.

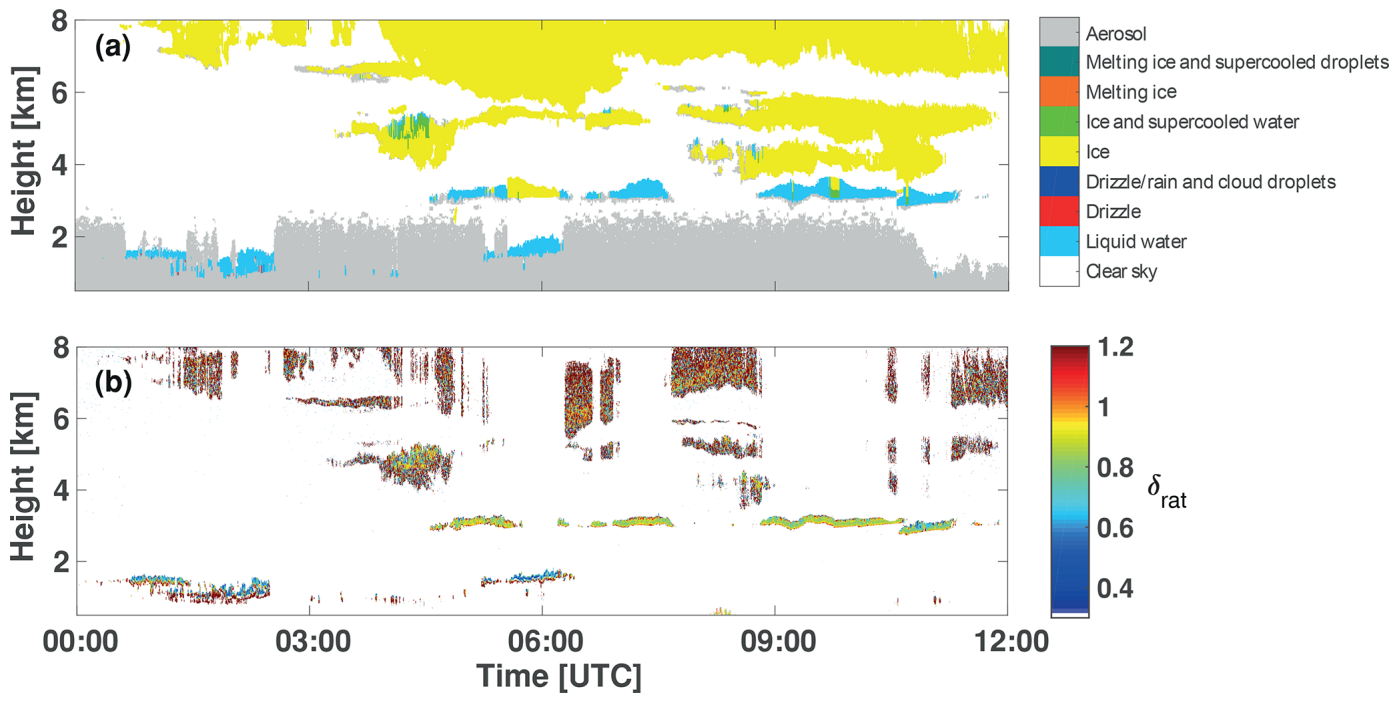

Figure 3. (a) Cloudnet target classification of the cloud layers shown in Fig. 2 and (b) ratio $\delta_{\text {rat }}=\delta_{\text {in }} / \delta_{\text {out }}$ measured with the dual-FOV polarization lidar Polly $\left(\mathrm{FOV}_{\text {in }}=1 \mathrm{mrad}, \mathrm{FOV}_{\text {out }}=2 \mathrm{mrad}\right)$.

Sect. 3.2). Then, we followed the data analysis strategy as illustrated in Fig. 8 in Part 1 and summarized in Table 1. We used $\bar{\delta}_{\text {rat }}=\bar{\delta}_{\text {in }} / \bar{\delta}_{\text {out }}$ for $\Delta z_{\text {ref }}=75 \mathrm{~m}$ to determine $R_{\mathrm{e}}\left(z_{\text {ref }}\right)$ by means of Eq. (26) (Part 1), and afterwards, $\bar{\delta}_{\text {in }}$ and $R_{\mathrm{e}}$ to determine $\alpha\left(z_{\text {ref }}\right)$ with Eq. (27). By means of the cloud extinction coefficient and the droplet effective radius, we finally obtained the liquid-water content $w_{1}\left(z_{\text {ref }}\right)$ with Eq. (4) and the droplet number concentration $N_{\mathrm{d}}\left(z_{\text {ref }}\right)$ with Eq. (6), again in Part 1.

As can be seen in Fig. 4 the shallow altocumulus field which developed in the pristine free troposphere in the Punta
Arenas area showed cloud extinction coefficients around $20 \mathrm{~km}^{-1}$ (75 $\mathrm{m}$ above the cloud base) and droplet effective radii of initially $10 \mu \mathrm{m}$ and later on around $7 \mu \mathrm{m}$. The liquidwater content was around $0.1 \mathrm{~g} \mathrm{~m}^{-3}$, and the cloud droplet number concentrations increased from initially $30 \mathrm{~cm}^{-3}$ to $50-80 \mathrm{~cm}^{-3}$ later on. The properties found are typical of stratiform cloud layers (stratocumulus, altocumulus) in the marine environment (Miles et al., 2000; Revell et al., 2019).

In Fig. 5, the uncertainties in the cloud retrieval products are shown. The impact of the different error contributions discussed in Sect. 5 of Part 1 is given. The influence of un- 


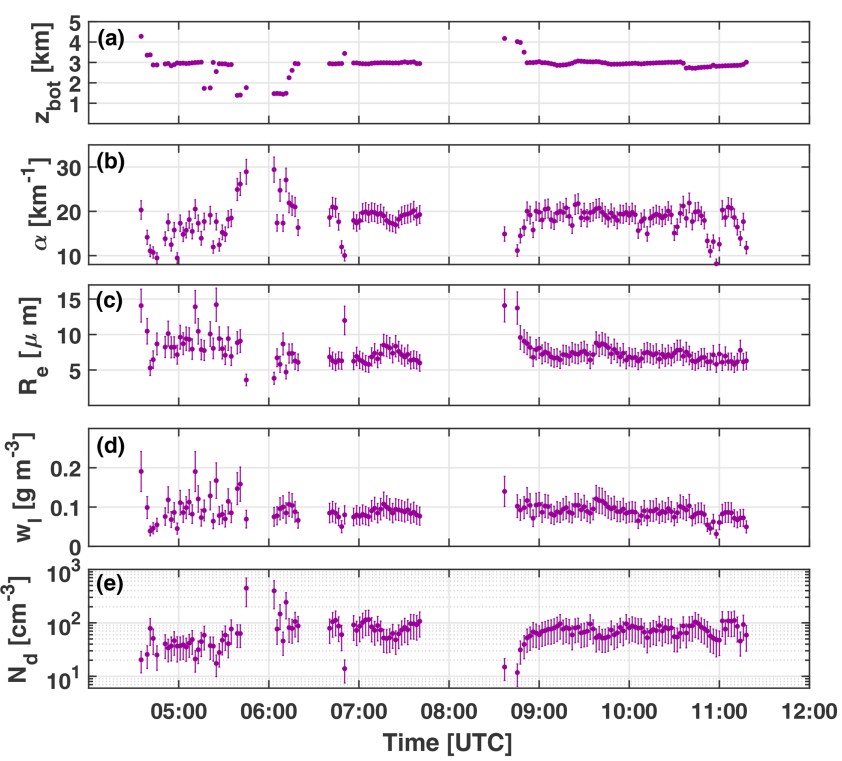

Figure 4. Dual-FOV polarization lidar observation of (a) cloud base height $z_{\text {bot }}$ of detected liquid cloud layers, (b) cloud extinction coefficient $\alpha\left(z_{\text {ref }}\right)$, (c) droplet effective radius $R_{\mathrm{e}}\left(z_{\text {ref }}\right)$, (d) liquidwater concentration $w_{1}\left(z_{\text {ref }}\right)$, and (e) droplet number concentration $N_{\mathrm{d}}\left(z_{\text {ref }}\right)$ for the liquid-water clouds mostly located between 3.0 and $3.5 \mathrm{~km}$ height shown in Fig. 2. $z_{\text {ref }}$ is $75 \mathrm{~m}$ above the cloud base. Time resolution is $120 \mathrm{~s}$. Error bars indicate the estimated overall uncertainty in the retrieved values.

certainties in the measured depolarization ratio profiles for the two FOVs computed using Eqs. (28) and (32) in Part 1 is in general small (on the order of $<5 \%$ relative error). The retrieval uncertainties caused by an error in the estimate of the cloud base (CB) height $z_{\text {bot }}( \pm 15 \mathrm{~m}$ uncertainty or $10 \%-15 \%$ relative error; see Eqs. (30) and (34) in Part 1) and caused by the theoretical (methodological) aspects (8$15 \%$ relative error; see Eqs. (29) and (33) in Part 1) dominate the overall uncertainties in the products. For both the cloud extinction coefficient $\alpha\left(z_{\text {ref }}\right)$ and droplet effective radius $R_{\mathrm{e}}\left(z_{\text {ref }}\right)$, the overall uncertainty is on the order of $15 \%-$ $25 \%$. The uncertainty in the $N_{\mathrm{d}}\left(z_{\text {ref }}\right)$ value depends on the uncertainties in $\alpha\left(z_{\text {ref }}\right)$ and $R_{\mathrm{e}}\left(z_{\text {ref }}\right)$ and is on the order of $50 \%$ according to the law of error propagation as indicated by a $50 \%$ uncertainty bar in Fig. 4e.

As discussed by Schmidt et al. $(2013,2014)$ a bias can be introduced when backscatter signals during periods with varying cloud base height resulting from up and downward motions are averaged. Then, in the lowest part of the cloud, signals from cloud-free and cloudy air parcels may be averaged which causes this bias. Such an effect cannot be excluded when using the dual-FOV Raman lidar method, whereby signals over 10-30 min must be averaged before cloud microphysical properties can be derived. However, the high temporal resolution now achievable with the new dual-
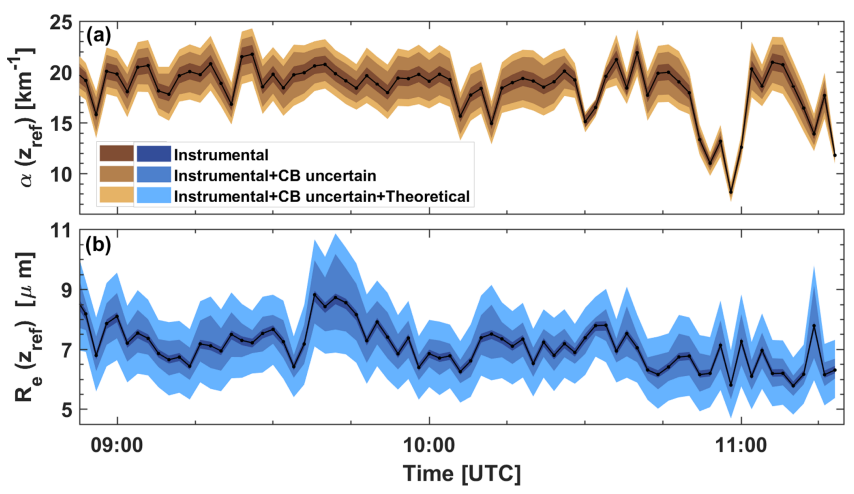

Figure 5. Contribution of the different error sources in the retrieval of the cloud extinction coefficient (a) and droplet effective radius (b) shown in Fig. 4. In (a), the impact of instrumental uncertainties is calculated with Eq. (32) in Part 1 (Jimenez et al., 2020), the uncertainty in the cloud base (CB) determination with Eq. (34), and theoretical uncertainties with Eq. (33) in Part 1. In (b), the impact of instrumental uncertainty is calculated with Eq. (28), the influence of the CB uncertainty with Eq. (30), and theoretical uncertainties with Eq. (29). The uncertainty in the CB determination and the methodological (theoretical) uncertainties dominate the overall retrieval uncertainties.

FOV polarization technique is of advantage in this respect, so we assume that related uncertainties are small.

Another uncertainty aspect arises from the fact that we observe the cloud layers with two different field of views (i.e., with two different eyes) and, thus, monitor two different portions (or cross sections) of the cloud in the horizontal plane. Our method assumes horizontally homogeneous cloud conditions, so that the multiple scattering effect is the only reason for differences in the measurements at the two different FOVs. However, in reality, horizontal variations in terms of droplet number concentration, size distribution, and cloud extinction coefficient always occur and can, in principle, affect the quality of the cloud retrieval products. We checked this potential impact by correlating the separately measured values of depolarization ratios for $\mathrm{FOV}_{\text {in }}$ and $\mathrm{FOV}_{\text {out }}$. The scatter in the data was very low and did not indicate any significant influence of horizontal cloud inhomogeneities on the ratio $\bar{\delta}_{\text {rat }}$ from which the effective radius of the cloud droplets is retrieved. The necessary signal averaging over 30 to $120 \mathrm{~s}$ may smooth out most of the existing inhomogeneities so that the overall impact is further decreased. A good sign for a negligible impact of horizontal fluctuations in the cloud properties is finally when the time series of the derived values for the different cloud parameters show a coherent behavior.

Figure 6 shows comparisons of our solutions for the cloud extinction coefficient and droplet effective radius with respective results obtained with the single-FOV (SFOV) polarization lidar method (Donovan et al., 2015) and a technique solely based on cloud radar observations of the radar reflectivity factor (Frisch et al., 2002). Here, we used our 
$35 \mathrm{GHz}$ cloud radar measurements simultaneously conducted at Punta Arenas. The SFOV lidar method is based on cloud simulations with a Monte Carlo multiple scattering model (Donovan et al., 2010) and, as a result of the lidar simulations, on computed lookup tables of the cross- and copolarized signal strengths as a function of cloud microphysical properties. In the case of the Polly instruments, the copolarized signal is given by the difference of the total minus the cross-polarized signal. The SFOV technique searches for the optimum solution of cloud microphysical properties (cloud extinction coefficient, droplet effective radius) which are consistent with the measured height profiles of the copolarized and cross-polarized lidar backscatter signals. The products are given as mean values for the lowest $100 \mathrm{~m}$ of the liquid-water cloud layer. For the comparison, we used our solutions for $75 \mathrm{~m}$ above the cloud base and the profile structures shown in Fig. (4) in Part 1 to compute the respective mean values of $\alpha$ and $R_{\mathrm{e}}$ for the lowest $100 \mathrm{~m}$ within the cloud layers. Note that we started from the SFOV lidar approach to develop the dual-FOV (DFOV) polarization lidar technique. One advantage of the SFOV polarization technique is that it can directly be used by widely distributed polarization lidars (with one FOV). The technique however requires a complicated treatment of the lidar data to perform the retrieval. On the other hand, the DFOV polarization technique allows a much more straightforward retrieval, exploiting the direct relationship between $\bar{\delta}_{\text {rat }}$ and $R_{\mathrm{e}}$.

As can be seen in Fig. 6a, the SFOV polarization lidar slightly underestimates the effective radius of the droplets compared to the other two methods. We used the $1 \mathrm{mrad}$ FOV channel here, as commonly used by widespread polarization lidars. If we use the $2 \mathrm{mrad}$ FOV channel, which is more sensitive to depolarization features caused by multiple scattering in water clouds, the agreement with the SFOV approach may improve.

The good agreement of our results with the respective cloud radar solution in Fig. $6 \mathrm{~b}$ corroborates the quality (accuracy) of our retrieval products. The radar method simply uses the high correlation between the radar reflectivity factor and effective radius. In this retrieval procedure, a lognormal droplet size distribution is assumed, and the cloud droplet number concentration $N_{\mathrm{d}}$ and the width of the size distribution are needed as input parameters. However, the dependence of the solutions on these input parameters is weak as the solution with different input values indicates. In Fig. 6, we assumed $N_{\mathrm{d}}=100 \mathrm{~cm}^{-3}$ (as a typical value for liquidwater clouds) and a logarithmic width of 0.29 as reported for marine stratocumulus over the Southern Ocean (Martin et al., 1994).

The agreement between the SFOV and DFOV solutions is very good in the case of the cloud extinction coefficient. The SFOV polarization lidar technique is obviously robust enough to retrieve the cloud extinction coefficient with good accuracy from the measured cloud depolarization ratio values. This observation is also consistent with Fig. 7 of Dono- van et al. (2015). The retrieved extinction coefficient was found to be not very sensitive to depolarization ratio calibration errors, in contrast to the retrieved values of the effective radius of the droplets.

\subsubsection{Aerosol and $\mathrm{CCN}$ conditions}

Figure 7 shows the aerosol conditions determined from the lidar observations at $\mathrm{FOV}_{\text {in }}=1 \mathrm{mrad}$ for this cloud event. We analyzed the altocumulus-free period from 07:45 to 08:45 UTC (see Fig. 2). It was still dark during this time, so we could use the Raman lidar option to determine the height profiles of the particle extinction coefficient at 355 and $532 \mathrm{~nm}$ wavelength (Baars et al., 2016; Hofer et al., 2017).

As can be seen in Fig. 7a, the particle extinction coefficient $\alpha_{\text {par }}$ at $532 \mathrm{~nm}$ was in the range of $5-10 \mathrm{Mm}^{-1}$ for the height range from 1.5 to $2.5 \mathrm{~km}$ height and even lower at the cloud base at $3 \mathrm{~km}$ of the cloud layer developing after this cloud-free period. The lidar-derived $532 \mathrm{~nm}$ aerosol optical thickness (AOT) was low, with values of 0.04 , consistent with the $500 \mathrm{~nm}$ AOT of 0.03 from the AERONET sun photometer observations on 22 March 2019 after sunrise (13:00-16:00 UTC) (AERONET, 2020).

The different relative humidity profiles in Fig. $7 \mathrm{c}$ indicated a comparably low relative humidity $(<70 \%)$ and thus a low particle water-uptake effect (Skupin et al., 2016; Haarig et al., 2017) in the height range from 1.6-2.2 km marked by dashed lines in Fig. 7. Our extinction-to- $N_{\mathrm{CCN}}$ conversion model, described in Sect. 6 in Part 1 (Jimenez et al., 2020) (see also Table 1), is applicable for these conditions. By assuming pure marine conditions and sea salt particles as $\mathrm{CCN}$, the conversion yields $N_{\mathrm{CCN}}=40 \mathrm{~cm}^{-3}$ for an assumed water supersaturation of $0.2 \%$ during droplet formation at the cloud base. Such low supersaturation values correspond to the occurrence of weak updrafts with vertical velocities of about $20 \mathrm{~cm} \mathrm{~s}^{-1}$ at the cloud base. By applying the continental fine-mode aerosol model, we obtain $160 \mathrm{~cm}^{-3}$ assuming urban haze or fire smoke conditions in the lower free troposphere above Punta Arenas. As shown in Fig. 4e, the cloud droplet number concentration $N_{\mathrm{d}}$ ranged from $50-100 \mathrm{~cm}^{-3}$.

HYSPLIT backward trajectories (Hybrid Single-Particle Lagrangian Integrated Trajectory Model) (Stein et al., 2015; Rolph et al., 2017; HYSPLIT, 2020), not shown here, indicated westerly winds from the Southern Ocean during the last $5 \mathrm{~d}$ before the air mass crossed the lidar station. According to the Ångström exponent in Fig. 7b, describing the wavelength dependence of the extinction coefficient in the short-wavelength range ( 355 to $532 \mathrm{~nm}$ ), traces of continental aerosol (haze or smoke) may have been present in the free troposphere over the lidar site. One option for the occurrence of fine-mode particles could be severe bush fires on the east coast of Australia in February and March 2019. The Ångström exponent is defined as $\ln \left(\alpha_{\mathrm{par}}\left(\lambda_{1}\right) / \alpha_{\mathrm{par}}\left(\lambda_{2}\right)\right) / \ln \left(\lambda_{2} / \lambda_{1}\right)$ and typically $0.35 \pm 0.2$ for the $355-532 \mathrm{~nm}$ wavelength range and $0.45 \pm 0.2$ in the case 

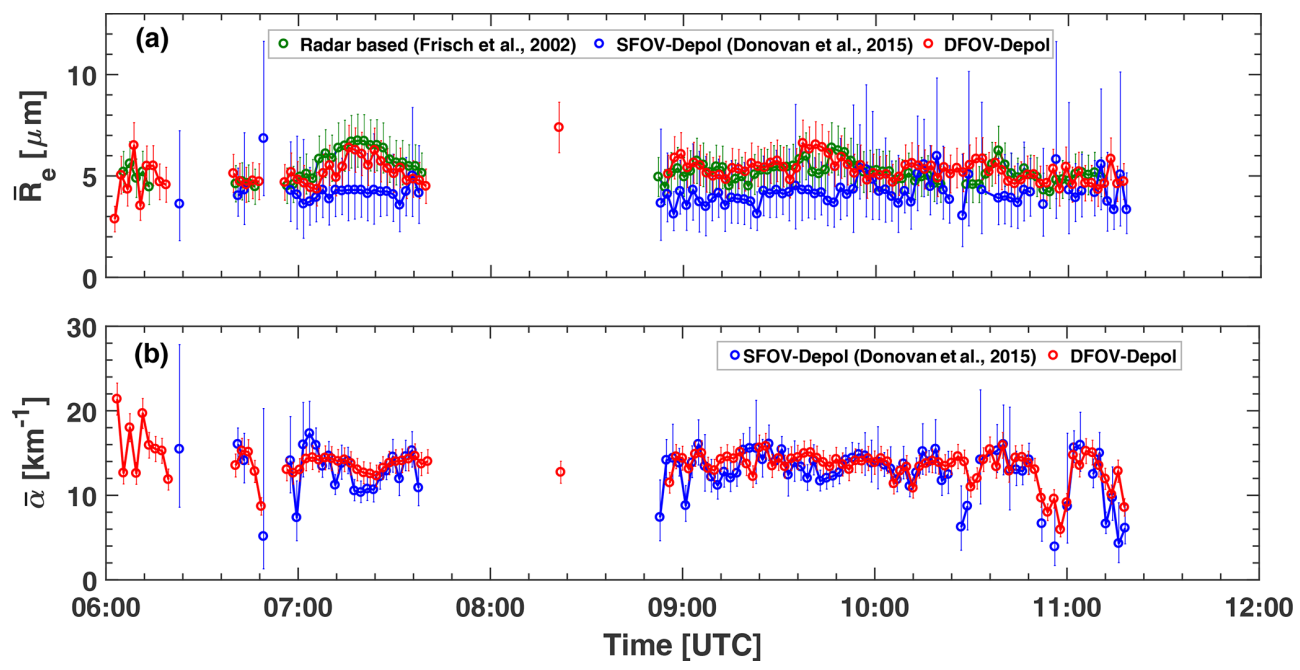

Figure 6. Comparison of (a) droplet effective radius values $\bar{R}_{\mathrm{e}}$ (mean values for the lowest $100 \mathrm{~m}$ in the liquid-water cloud layer) and (b) respective mean extinction coefficient values $\bar{\alpha}$ obtained with the single-FOV polarization lidar method (SFOV-Depol) (Donovan et al., 2015) and the dual-FOV polarization lidar technique (DFOV-Depol) for the case shown in Fig. 4. In addition, the results (in green) obtained with a cloud radar approach (Frisch et al., 2002) are shown in (a). Observations of the radar reflectivity factor performed with the LACROS $35 \mathrm{GHz}$ cloud radar at Punta Arenas are used here. Error bars indicate the uncertainty range.

of the widely used Angström exponent for the visible-nearIR wavelength spectrum (440-870 $\mathrm{nm}$ spectral range). Such low Ångström exponents clearly below 1 were observed at heights below $1 \mathrm{~km}$ in Fig. $7 \mathrm{~b}$.

However, it is more likely that pure marine conditions prevailed but that the marine coarse-mode particle fraction (large sea salt particles) was widely removed by sedimentation or cloud events in which the large sea salt particles were preferably consumed as $\mathrm{CCN}$ and then removed by rainout. As a response to the removal of coarse-mode particles, the Ångström exponent increases. The apparent discrepancy between the low marine $N_{\mathrm{CCN}}$ of about $40 \mathrm{~cm}^{-3}$ and the much higher $N_{\mathrm{d}}$ values $\left(80-100 \mathrm{~cm}^{-3}\right)$ is possibly caused by the $0.2 \%$ supersaturation assumption in our $N_{\mathrm{CCN}}$ retrieval. The Doppler lidar of LACROS showed the occurrence of gravity wave structures with a pronounced updraft period $(45 \mathrm{~min})$ from about 08:45 to 09:30 UTC on 22 March 2019 (when a cloud layer formed after the cloud-free period) and vertical winds mostly between 0.5 and $1 \mathrm{~m} \mathrm{~s}^{-1}$, and partly exceeding $1 \mathrm{~m} \mathrm{~s}^{-1}$, so that the water supersaturation was probably clearly higher than $0.5 \%$. At these higher supersaturation conditions the $\mathrm{CCN}$ concentration is higher by a factor of about 2 than the value for the $0.2 \%$ supersaturation level, as discussed in Mamouri and Ansmann (2016) and recently in Regayre et al. (2020) for Southern Ocean marine CCN conditions. In addition, at such strong vertical winds, even nonsea-salt marine sulfate particles (nss-SO ${ }_{4}^{2-}$ ) (Fossum et al., 2020) may have served as CCN. The sulfate-particle-related $\mathrm{CCN}$ concentration can be 1 to 2 orders of magnitude higher than the sea-salt-particle-related CCN numbers (Fossum et al., 2020). This aerosol species is not considered in the ma- rine conversion model (Mamouri and Ansmann, 2016) presented in Sect. 6 of Part 1.

\subsection{Case study of 23 February 2019}

The second case of the DACAPO-PESO campaign is selected to highlight the significantly improved potential of lidar to contribute to ACI studies with a focus on liquid-water clouds. By means of the new dual-FOV polarization lidar technique, cloud and aerosol information can be derived with high temporal resolution which allows us to resolve different phases of the cloud evolution and life cycle and to investigate the impact of individual updrafts on the droplet nucleation rate, droplet growth, and corresponding evolution of the effective radius and the $N_{\mathrm{d}}-N_{\mathrm{CCN}}$ relationship in great detail.

Schmidt et al. $(2014,2015)$ developed a new strategy to investigate $\mathrm{ACI}$ by integrating vertical wind observations with a Doppler lidar. The closest relationship between the number of CCN below the cloud base and the freshly formed cloud droplets was found during updraft periods. The ACI parameter $E_{\mathrm{ACI}, \alpha_{\mathrm{par}}}\left(N_{\mathrm{d}}, \alpha_{\mathrm{par}}\right)$ (see Table 1 and the discussion in Sect. 6 in Part 1) was around 0.4 when ignoring the meteorological impact (vertical motion) and about 0.8 when lidar observations exclusively performed during updraft times were considered (Schmidt et al., 2015). However, the database of Schmidt et al. $(2014,2015)$ was small ( $<30$ individual cloud cases). When using the dual-FOV Raman lidar technique, long signal averaging times are required. More than 200 cloud events were collected, but only in 27 cases were the observational constraints fulfilled (need for clear skies below the cloud layers over the long signal averaging times of 10-30 min and also a relatively constant cloud base height 

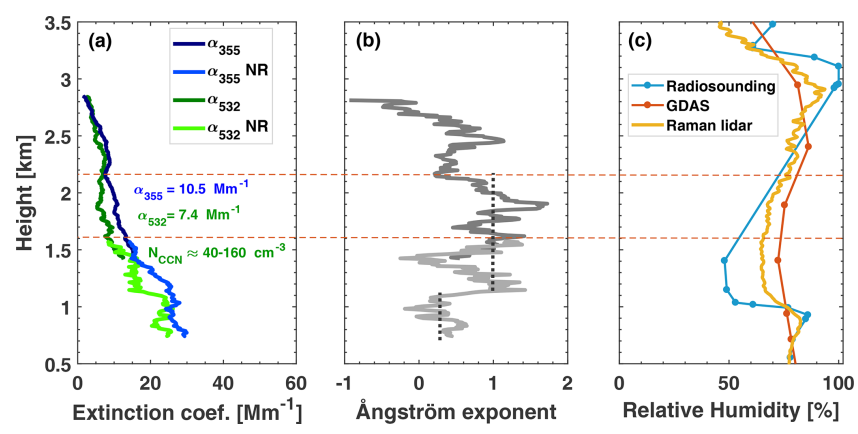

Figure 7. Aerosol observation with the dual-FOV polarization Raman lidar on 22 March 2019 during the altocumulus-free period from 07:45-08:45 UTC (see Figs. 2 and 4). (a) Particle extinction coefficient at 355 and $532 \mathrm{~nm}$ (NR indicates the determination from Raman signal profiles measured with the near-range of $\mathrm{FOV}_{\text {out }}$ telescope), (b) Ångström exponent (355-532 nm spectral range) computed from the extinction profiles in (a), and (c) relative humidity profiles, calculated from the Raman lidar observation of the water vapor mixing ratio (for the time period from 07:45-08:45 UTC, in yellow), by using the respective GDAS temperature profile (not shown), relative humidity taken from the GDAS data set (orange), and as measured with the Punta Arenas radiosonde (blue, launched at 12:00 UTC). The mean values of the particle extinction coefficients $\alpha_{355}$ at $355 \mathrm{~nm}$ and $\alpha_{532}$ at $532 \mathrm{~nm}$ for the height range from $1.6-2.15 \mathrm{~km}$ (driest region, indicated by dashed horizontal lines) are given as numbers in (a). The layer mean $532 \mathrm{~nm}$ extinction coefficient is used to derive the $N_{\mathrm{CCN}}$ range by assuming pure marine conditions (minimum value) and pure urban haze conditions (maximum value) and a supersaturation of $0.2 \%$ during droplet nucleation events. The dashed vertical lines in (b) indicate different Ångström values for the boundary layer and for the relatively dry part of the free troposphere below the cloud deck.

during these $10-30 \mathrm{~min}$ ). These restrictions were required to avoid biases in the data analysis and thus allow a trustworthy ACI study. All these shortcomings are widely overcome now by using the new dual-FOV polarization lidar technique.

We start with Fig. 8a which shows a 6 h cloud measurement at Punta Arenas on 23 February 2019. Liquid-water cloud parcels permanently formed at the top of the convective summertime planetary boundary layer (PBL) between 15:00 and 21:00 local time (18:00-24:00 UTC). HYSPLIT backward trajectories (not shown) indicated pure marine conditions with an airflow from southwest (from the Southern Ocean). GDAS relative humidity (RH) values ranged from $60 \%-65 \%$ (at $500 \mathrm{~m}$ height) and $75 \%-85 \%$ (at $1000 \mathrm{~m}$ height) and were around $>95 \%$ about $100 \mathrm{~m}$ below the cloud base during the 18:00-24:00 UTC period (GDAS, 2020). The aerosol particle extinction coefficient $\alpha_{\mathrm{par}}$ decreased with time and indicated a significant reduction of aerosol particles during the last $2 \mathrm{~h}$ of the measurement period (22:0024:00 UTC; see Table 2). The particle extinction coefficient is calculated from the measured aerosol backscatter coefficient multiplied by a typical marine extinction-to-backscatter ratio of $25 \mathrm{sr}$ at $532 \mathrm{~nm}$ (more details of the determination of
Table 2. Mean values and standard deviations of cloud properties observed in the liquid-water cloud layer at $3 \mathrm{~km}$ height on 23 February 2019. The aerosol properties for the height range from 375$600 \mathrm{~m}$ below the cloud base are given in addition. During the selected averaging periods (before and after 22:00 UTC), very different cloud and aerosol properties were found.

\begin{tabular}{lrr}
\hline & $18: 00-22: 00$ UTC & $22: 00-24: 00 \mathrm{UTC}$ \\
\hline$N_{\mathrm{d}}, \mathrm{cm}^{-3}$ & $42.4 \pm 46.3$ & $21.4 \pm 15.4$ \\
$R_{\mathrm{e}}, \mu \mathrm{m}$ & $8.5 \pm 2.7$ & $10.4 \pm 2.7$ \\
$\alpha, \mathrm{km}^{-1}$ & $10.0 \pm 2.3$ & $9.3 \pm 1.8$ \\
$w_{1}, \mathrm{gm}^{-3}$ & $0.054 \pm 0.015$ & $0.063 \pm 0.02$ \\
$N_{\mathrm{CCN}}, \mathrm{cm}^{-3}$ & $110 \pm 21$ & $72 \pm 14$ \\
$\alpha_{\mathrm{par}}, \mathrm{km}^{-1}$ & $0.025 \pm 0.006$ & $0.015 \pm 0.003$ \\
\hline
\end{tabular}

backscatter coefficient profiles below a cloud deck are given in Sect. 6.1 in Part 1).

Figure $8 \mathrm{~b}$ shows the convective structures of the PBL in terms of the vertical wind component measured with the zenith-pointing Doppler lidar of LACROS (Cloudnet, 2020). Varying periods with upward (orange) and downward motions (green) were observed. Most updraft velocities were $<0.5-0.7 \mathrm{~m} \mathrm{~s}^{-1}$; however some strong updrafts with velocities $>1 \mathrm{~m} \mathrm{~s}^{-1}$ occurred as well. The up- and downdrafts modulated cloud formation and cloud base height variations. Water uptake by the aerosol particles at relative humidity $>75 \%$ (close to the cloud base) influenced the strength of the lidar return signals, especially during upwind situations. The dashed lines in Fig. 8a follow the variations of the cloud base height $z_{\text {bot }}$ and indicate 10 further height levels from $75-750 \mathrm{~m}$ below the cloud base. These height levels $\left(z_{\text {aer }}\right.$ in the ACI sketch in Fig. 4 of Part 1) are used in the discussion of the results regarding ACI below.

Figure 9 presents the time series of the cloud droplet number concentration $N_{\mathrm{d}}$ for the height $z_{\text {ref }}=z_{\text {bot }}+75 \mathrm{~m}$ (see Fig. 4 of Part 1) obtained from the dual-FOV polarization lidar measurements together with the vertical wind indicator (orange for updraft, green for downdraft) and the aerosol proxies $\alpha_{\mathrm{par}}$ and $N_{\mathrm{CCN}}$. The aerosol proxies are mean values for the height range from $375-600 \mathrm{~m}$ below the cloud base at $z_{\text {bot }}$ and thus for the height range from $z_{\text {aer }}=z_{\text {bot }}-375 \mathrm{~m}$ to $z_{\text {aer }}=z_{\text {bot }}-600 \mathrm{~m}$ according to Fig. 4 in Part 1. The temporal resolution in Fig. 9 is $1 \mathrm{~min}$. The marine aerosol conversion parameterization (Mamouri and Ansmann, 2016) is applied to obtain $N_{\mathrm{CCN}}$ (see Table 1; more explanations are given in Sect. 6 in Part 1). This conversion corrects for aerosol wateruptake effects for a typical marine RH of $80 \%$ and holds for the water supersaturation level of $0.2 \%$. Error bars indicate the retrieval uncertainty of $20 \%$ (marine particle extinction coefficient $\left.\alpha_{\mathrm{par}}\right)$ and $50 \%\left(N_{\mathrm{d}}, N_{\mathrm{CCN}}\right)$.

Figure 9 shows that the cloud droplet number concentration $N_{\mathrm{d}}$ varied strongly and was clearly correlated with updraft occurrence during the 19:30-24:00 UTC time period, 


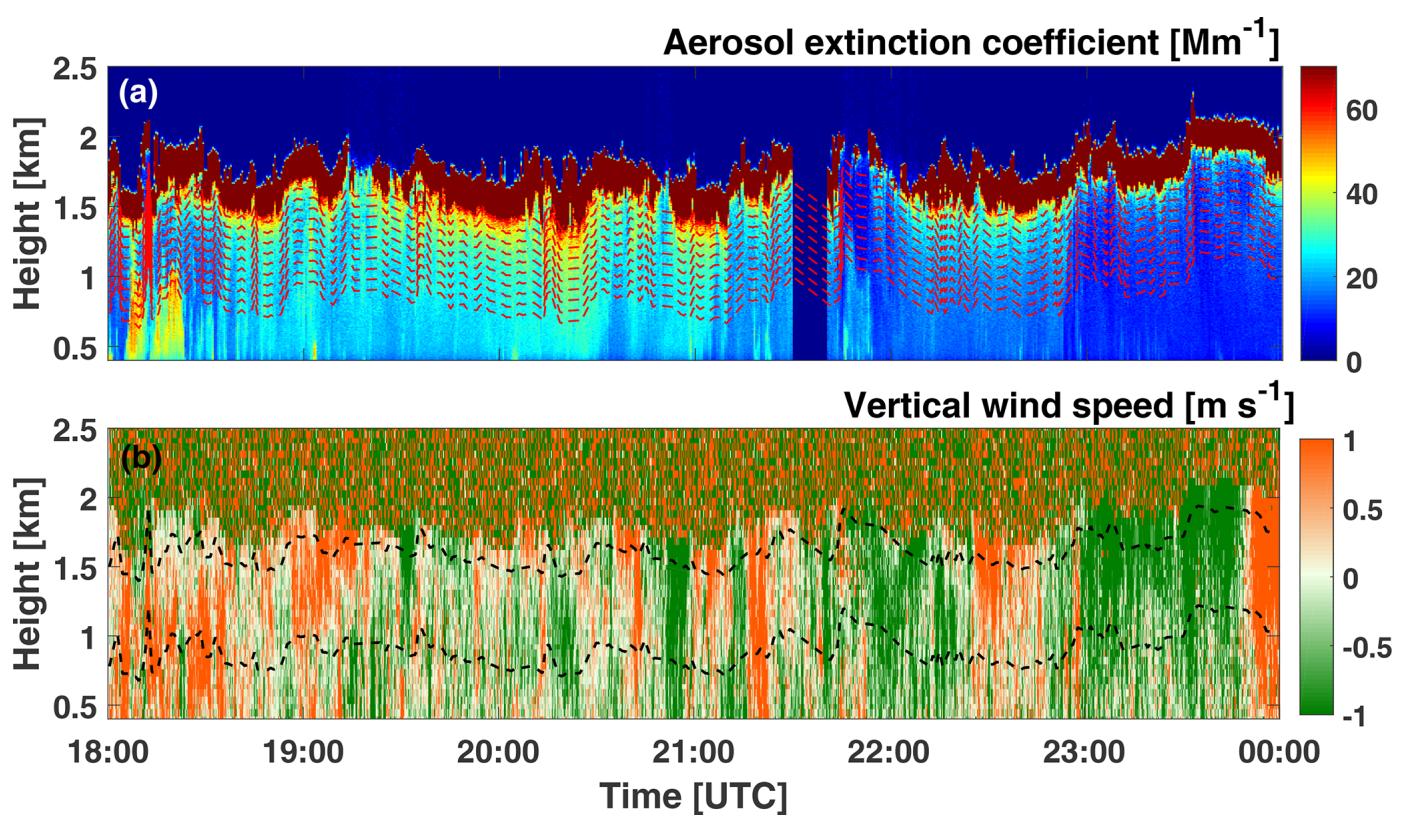

Figure 8. Lidar observation of the convective cloud-topped planetary boundary layer in the afternoon and evening of the summer day of 23 February 2019. (a) Aerosol extinction coefficient (blue to yellow colors) up to the base of the stratocumulus layer (dark red) at around $1500 \mathrm{~m}$ height and (b) vertical wind component (orange: upward motion, green: downward motion) measured with the zenith-pointing Doppler lidar of the LACROS facility. The cloud base strongly varies with the permanently changing updraft and downdraft conditions. Dashed red curves in (a) show height levels of constant distance of 75 to $750 \mathrm{~m}$ from the cloud base. The dashed black lines in (b) show the cloud base height $z_{\text {bot }}$ and the height level $750 \mathrm{~m}$ below the cloud base. For these height levels, aerosol proxies for the ACI studies are computed as discussed below.

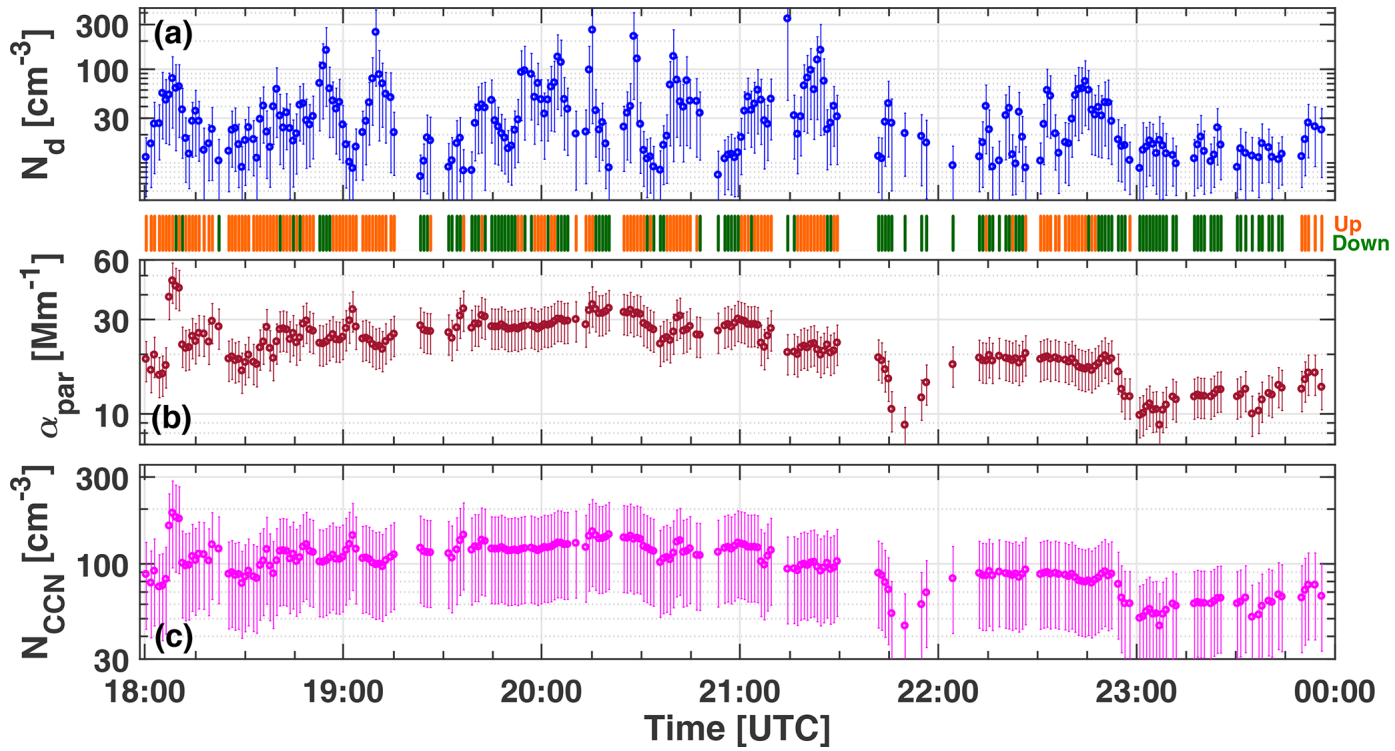

Figure 9. (a) Cloud droplet number concentration $N_{\mathrm{d}}$ for the height of $z_{\mathrm{ref}}=z_{\text {bot }}+75 \mathrm{~m}$ within the stratocumulus layer shown in Fig. 8 . Below a, the vertical wind indicator (orange: updraft, green: downdraft) is shown. (b) Particle extinction coefficient $\alpha_{\text {par }}$ (mean value for the height range from 375 to $600 \mathrm{~m}$ below the cloud base). (c) CCN concentration $N_{\mathrm{CCN}}$ obtained from the extinction coefficient (in b) by using the marine conversion parameters (Sect. 6 in Part 1) (Jimenez et al., 2020). Temporal resolution is 1 min. Error bars indicate the uncertainty range. 
whereas the aerosol proxies $N_{\mathrm{CCN}}$ and $\alpha_{\text {par }}$ were likewise smooth functions of time. However, the true or actual $N_{\mathrm{CCN}}$ values probably showed large variations because the $\mathrm{CCN}$ level (actually occurring) depends on actual updraft speed and the related actually occurring supersaturation level. For updraft velocities of $1 \mathrm{~m} \mathrm{~s}^{-1}$ and corresponding supersaturation exceeding $0.5 \%, N_{\mathrm{CCN}}$ is approximately a factor of 2 higher than the ones shown for the fixed $0.2 \%$ water supersaturation as outlined in Mamouri and Ansmann (2016) and already pointed out in Sect. 4.1.

On average, $N_{\mathrm{d}}$ ranged from $20-100 \mathrm{~cm}^{-3}$ before 21:30 UTC and $10-30 \mathrm{~cm}^{-3}$ later on. Peak values exceeded $200 \mathrm{~cm}^{-3}$. The aerosol parameters $N_{\mathrm{CCN}}$ and $\alpha_{\mathrm{par}}$, indicating clean conditions (with horizontal visibility $>50 \mathrm{~km}$ ), were mostly in the range of $20-40 \mathrm{Mm}^{-1}$ before $21: 15$ UTC and $10-25 \mathrm{Mm}^{-1}$ later on in the case of $\alpha_{\mathrm{par}}$ and $>100 \mathrm{~cm}^{-3}$ before 21:15 UTC and clearly $<100 \mathrm{~cm}^{-3}$ later on in the case of $N_{\mathrm{CCN}}$. The decrease of $N_{\mathrm{d}}$ with time is in line with the decrease of $N_{\mathrm{CCN}}$ and $\alpha_{\mathrm{par}}$. Table 2 summarizes the aerosol and cloud observations and contains mean values of all derived aerosol and cloud properties for two time periods characterized by different aerosol conditions.

Besides aerosol and cloud correlations, our measurements allow us to look into the effect of vertical wind velocity (especially of updrafts) on the observed cloud products. The number of aerosol particles and the updraft velocity (and accompanying adiabatic cooling) (Reutter et al., 2009) controls $\mathrm{CCN}$ activation and droplet growth. Upward movements affect the water vapor saturation pressure in the cloud base region. The stronger the updraft is, the larger the water supersaturation is, enabling aerosol particles to become activated and grow. In Fig. 10, the impact of upward (and downward) motions on the measured cloud properties $N_{\mathrm{d}}, R_{\mathrm{e}}$, and $\alpha_{\text {par }}$ is illuminated for the observation on 23 February 2019. For comparison, we also included the respective variations of the aerosol proxy $N_{\mathrm{CCN}}$.

Such correlations of $N_{\mathrm{d}}$ and $R_{\mathrm{e}}$ with vertical velocity at the cloud base are new options of combined dual-FOV and Doppler lidar profiling. As can be seen, very clear correlations were not found. A pronounced influence of updraft speed on $N_{\mathrm{d}}$ and $R_{\mathrm{e}}$ cannot be expected in this case of a longlived, well-developed stratocumulus cloud deck. At such preexisting cloud conditions there is a competition between droplet nucleation and water uptake by the existing droplets in the case of a given supersaturation. Advection and diffusion processes mix different droplet concentrations together. Besides condensation of water vapor on existing droplets and new droplet formation, collision-coalescence processes shape the size distribution measured over the lidar station. All cloud features observed are related to processes that occurred upstream of the lidar. However, even in these cases of complex cloud processes, we expect that a residual effect of the aerosol concentration variations found on the droplet microphysical properties during updraft periods should be detectable. Updraft speeds of $0-70 \mathrm{~cm} \mathrm{~s}^{-1}$ occurred most of-
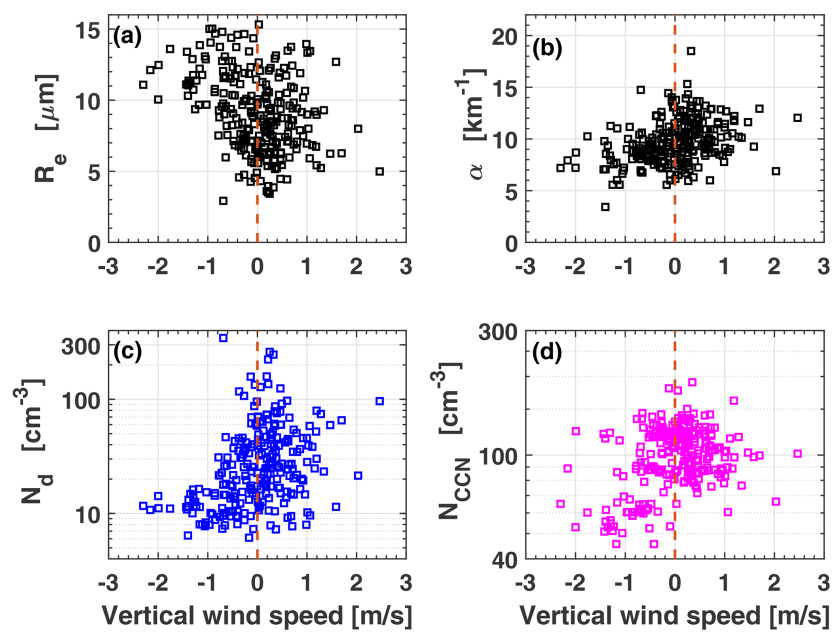

Figure 10. Correlation of retrieved cloud properties (droplet effective radius $R_{\mathrm{e}}$, number concentration $N_{\mathrm{d}}$, and $532 \mathrm{~nm}$ lightextinction coefficient $\alpha$ ) and aerosol CCN concentration $N_{\mathrm{CCN}}$ (for a fixed water supersaturation level of $0.2 \%$ ) vs. vertical wind measured with Doppler lidar at the cloud base. The data in Fig. 9 are used. The data are observed with 1 min temporal resolution in a well-developed stratocumulus deck at the top of the pristine marine boundary layer.
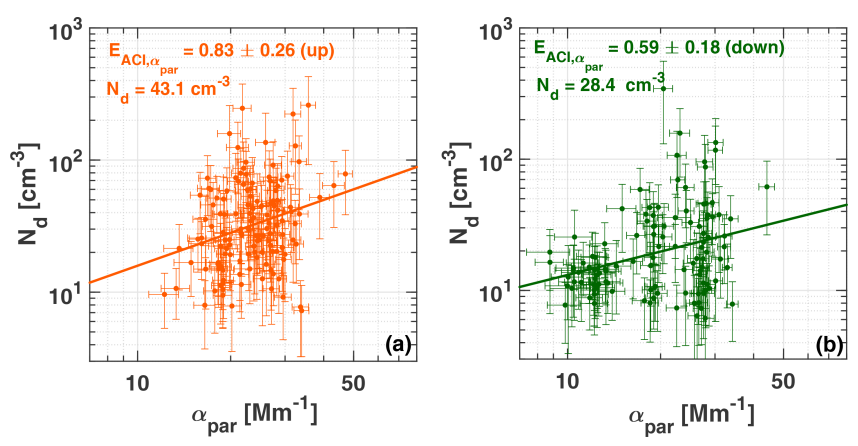

Figure 11. Cloud droplet number concentration $N_{\mathrm{d}}$ (for height $z_{\text {ref }}=75 \mathrm{~m}$ above the cloud base) vs. aerosol particle extinction coefficient $\alpha_{\text {par }}$, separately for (a) updraft and (b) downdraft periods.

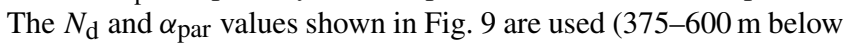
the cloud base). In total, almost 260 values were available for the regression analysis. Error bars show the uncertainties in the $N_{\mathrm{d}}$ and

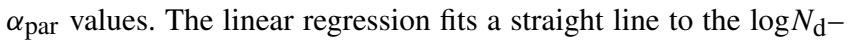
$\log \alpha_{\text {par }}$ data field with the slope $E_{\mathrm{ACI}, \alpha_{\mathrm{par}}}=0.87 \pm 0.26$ (orange slope) and $0.58 \pm 0.17$ (green slope). The mean droplet number concentration (given as numbers) was about $50 \%$ higher during the updraft periods than during the downdraft periods.

ten. For these weak to moderate updraft velocities $N_{\mathrm{d}}$ and $N_{\mathrm{CCN}}$ (for the supersaturation of $0.2 \%$ ) were then found in the range from $15-100$ and $75-200 \mathrm{~cm}^{-3}$, respectively. Obviously the true supersaturation was about $0.1 \%-0.15 \%$ (to obtain an activation ratio $N_{\mathrm{d}} / N_{\mathrm{CCN}}=1$ ). New droplet formation and growth of existing droplets by water uptake led to a slight increase of the cloud extinction coefficient in many 
cases. A weak reduction of the mean effective radius during upward motions may indicate new droplet nucleation in the presence of existing droplets.

Our observations of $N_{\mathrm{d}}$ and $N_{\mathrm{CCN}}$ are in good agreement with values presented by Revell et al. (2019). In this modelbased study, simulated $N_{\mathrm{CCN}}$ values (for a supersaturation of $0.2 \%$ ) were in the range from $50-80 \mathrm{~cm}^{-3}$ during the late summer season (February and March), and $N_{\mathrm{d}}$ showed values from $30-50 \mathrm{~cm}^{-3}$ for boundary layer clouds at $800 \mathrm{~m}$ height under pure marine conditions of the Southern Ocean. According to the recent publication of Regayre et al. (2020), $N_{\mathrm{CCN}}$ is usually underestimated by a factor of 2 in models focusing on aerosols and clouds in the Southern Ocean. Our lidar-derived $N_{\mathrm{CCN}}$ values are in very good agreement with the CCN numbers presented by Regayre et al. (2020) of usually $100-200 \mathrm{~cm}^{-3}$. These authors constrained their simulations to recent CCN observations aboard a Russian research vessel traveling around the entirety of Antarctica (Schmale et al., 2019). Our findings are also in reasonable agreement with airborne in situ observations of $N_{\mathrm{d}}$ and $N_{\mathrm{CCN}}$ over the Southeast Pacific stratocumulus cloud regime west of northern Chile (Zheng et al., 2011; Painemal and Zuidema, 2013).

Some caution has to be exercised in the interpretation of the results in Fig. 10 because of the uncertainties in the retrieval products discussed above (case study 1) and because of the assumptions made in the development of the dualFOV polarization lidar technique. We assume subadiabatic conditions and corresponding profile structures for the different cloud parameters as shown in Fig. 4 of Part 1 for the lowermost $75 \mathrm{~m}$ of the cloud layer. We also assume a gamma size distribution to describe the droplet size spectrum. These assumptions may no longer hold for an aged, preexisting cloud layer (especially not during downdraft periods) in which droplet collision and coalescence processes, entrainment, and droplet evaporation take place. However, the gamma size distribution and subadiabatic cloud conditions were introduced to develop our dual-FOV lidar method with a focus on the most interesting scenarios (updraft periods). The new method is primarily based on the strong relationship between the measured ratio $\bar{\delta}_{\text {rat }}=\bar{\delta}_{\text {in }} / \bar{\delta}_{\text {out }}$ and the droplet effective radius $R_{\mathrm{e}}$ and the clear relationship between the depolarization ratio $\bar{\delta}_{\text {in }}$ (for FOV $\mathrm{FO}_{\text {in }}$ ) and the cloud extinction coefficient $\alpha$ for a given $R_{\mathrm{e}}$ value, known from the first part of the retrieval procedure.

Disregarding the complex cloud structures, processes, and features found, we computed the ACI parameter $E_{\mathrm{ACl}, \alpha_{\mathrm{par}}}\left(N_{\mathrm{d}}, \alpha_{\mathrm{par}}\right)$ (see Table 1 and Sect. 6 in Part 1 for more explanations). In Fig. 11, the correlation between the derived $N_{\mathrm{d}}$ and measured $\alpha_{\mathrm{par}}$ values (in Figs. 9 and 10) are considered separately for updraft and downdraft periods. We use the particle extinction coefficient $\alpha_{\text {par }}$ (and not $N_{\mathrm{CCN}}$ ) in the correlation because this quantity is directly obtained from the lidar observations with a low uncertainty of $20 \%$. Disregarding the aerosol proxy used, we notice a large scatter in the correlated data. This is typical of aerosol and cloud

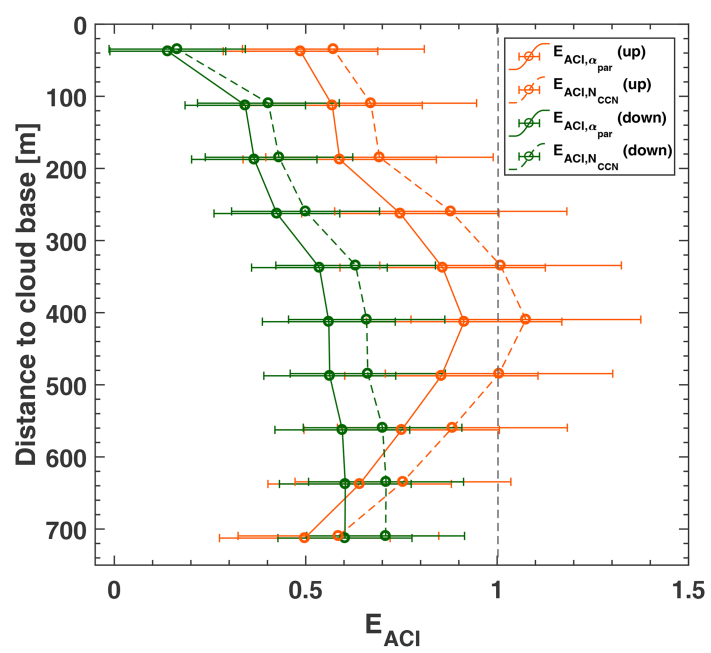

Figure 12. ACI efficiency parameter $E_{\mathrm{ACI}}$ (see Table 1 and Sect. 6 in Part 1 for detailed explanations) as a function of $N_{\mathrm{d}}$ and $\alpha_{\mathrm{par}}$ (solid curves, $E_{\mathrm{ACI}, \alpha_{\mathrm{par}}}$ ) and as a function of $N_{\mathrm{d}}$ and $N_{\mathrm{CCN}}$ (dashed curve, $E_{\mathrm{ACI}, \mathrm{N}_{\mathrm{CCN}}}$ ), separated for updraft periods (orange) and downdraft periods (green). Different values of aerosol proxies $\alpha_{\text {par }}$ and $N_{\mathrm{CCN}}$ for different layers (with $75 \mathrm{~m}$ vertical depth and increasing distance from the cloud base towards lower heights) are considered in the calculations of the four $E_{\mathrm{ACI}}$ parameters (as explained in Fig.11). The ACI efficiencies are assigned to the center heights of these $75 \mathrm{~m}$ deep aerosol layers for which the aerosol proxies were determined. $E_{\mathrm{ACI}}$ values around $400 \mathrm{~m}$ below the cloud base are obviously not affected by aerosol water-uptake effects which tend to widely smooth out a well-defined and strong correlation between aerosol proxy and cloud droplet number concentration. Error bars indicate the uncertainty in the determination of the slopes of the linear regression analysis.

parameters determined in well-developed, preexisting liquidwater cloud layers (McComiskey et al., 2009). As mentioned above, the large scatter is caused by the strong variability of $N_{\mathrm{d}}$ (as a function of the varying vertical wind conditions) compared to the low variability in the particle extinction coefficient which is not a function of vertical wind velocity. To obtain $E_{\mathrm{ACI}, \alpha_{\mathrm{par}}}\left(N_{\mathrm{d}}, \alpha_{\mathrm{par}}\right)$ a linear regression analysis is applied to the $\log \left(N_{\mathrm{d}}\right)-\log \left(\alpha_{\mathrm{p}}\right)$ data field. $E_{\mathrm{ACl}, \alpha_{\mathrm{par}}}\left(N_{\mathrm{d}}, \alpha_{\mathrm{par}}\right)$ is equal to the slope of the regression line. As expected, the aerosol impact on $N_{\mathrm{d}}$ is stronger for upward motions. However, we should emphasize again that we present just one case study (in order to show the potential of the dual-FOV lidar) so that general conclusions on the relationship between $N_{\mathrm{d}}$ and $N_{\mathrm{CCN}}$ can not be drawn in this stage of data analysis. Presently we analyze the entire Punta Arenas data set (collected in 2019-2020) along the data analysis steps presented here.

As a final task, we applied such correlation studies and regression analysis as presented in Fig. 11 to the full sets of $N_{\mathrm{d}}$, $\alpha_{\mathrm{par}}$, and $N_{\mathrm{CCN}}$ data. We performed regression analyses with different sets of aerosol proxies for different height levels $z_{\text {aer }}$ below the cloud base height $z_{\text {bot }}$ (as illustrated in Fig. 4 in 
Part 1 and indicated by the 10 dashed lines in Fig. 8a) to investigate to what extent water uptake corrupts the ACI study. The result is shown in Fig. 12.

The respective ACI efficiency values $E_{\mathrm{ACI}}$ are assigned to the heights of the aerosol layers (with respect to the cloud base) of which the aerosol proxies were considered in the $E_{\mathrm{ACI}}$ computations. This way of presenting the ACI efficiency values allows us to check the impact of water uptake by the marine particles when the relative humidity steadily increases and reaches $100 \%$ at the cloud base. As can be seen, the ACI efficiency $E_{\mathrm{ACI}}$ for well-defined updraft conditions decreases from values close to 1 (the optimum value for the expected strong impact of marine particles on the droplet number concentration) at heights around $400 \mathrm{~m}$ below the cloud base to values around 0.5 very close to the cloud base. Obviously, water uptake leads to a broadening of the range of observable extinction coefficients. For dry or almost dry particles, the extinction coefficients vary over a more narrow range, so the relative increase of the directly measured $\log \left(\alpha_{\text {par }}\right)$ is proportional to the relative increase in $\log N_{\mathrm{d}}$. This is no longer the case when all particles grow by water uptake. Then the increase of $\log \left(\alpha_{\mathrm{par}}\right)$ is linked to a much lower relative increase of the droplet number concentration (lower by a factor of almost 2). For downdraft periods the decrease of $E_{\mathrm{ACI}}$ with water-uptake effects is less clear and pronounced as can be seen in Fig. 11 because of the generally not well-defined link between droplet nucleation and available CCN.

It is interesting to note at the end that Shinozuka et al. (2015) found that the maximum value of $E_{\mathrm{ACI}, \alpha_{\mathrm{par}}}\left(N_{\mathrm{d}}, \alpha_{\mathrm{par}}\right)$ can only be about $0.8-0.85$, i.e., when the aerosol particle extinction coefficient $\alpha_{\mathrm{p}}$ is used as aerosol proxy. $E_{\mathrm{ACI}}=0.9-$ 1.0 is only possible when $N_{\mathrm{CCN}}$ is considered as shown in Fig. 12. The reason for this is that $N_{\mathrm{CCN}}$ is proportional to $\alpha_{\mathrm{par}}^{0.85}$ and not to $\alpha_{\text {par }}$ in Eq. (36) in Part 1.

\section{Summary, conclusions, and outlook}

In a companion article (Jimenez et al., 2020), we presented a new polarization-lidar-based approach to derive microphysical properties in the lower part of pure liquid-water clouds. Extended simulations were performed regarding the relationship between cloud microphysical and light-extinction properties and the cloud depolarization ratio measured with lidar at two different FOVs. These simulations served as the basis for the development of the new dual-FOV polarization lidar method. The effective radius of the cloud droplets and the cloud light-extinction coefficient in the lowest $50-100 \mathrm{~m}$ of the cloud layer can be derived with a relative error of $20 \%-$ $25 \%$. From the quantities, the cloud droplet number concentration can be computed with an error of the order of $50 \%$.

In Part 2, the new lidar technique was combined with the aerosol polarization lidar method, which enables the retrieval of CCN concentrations below the cloud base, and with
Doppler lidar observations of the vertical wind component and thus of updraft and downdraft occurrence at the cloud base. We integrated the novel dual-FOV polarization lidar technique into a multiwavelength polarization Raman lidar (Polly), which is now involved in the long-term DACAPOPESO field campaign in Punta Arenas, southern Chile, at the southernmost tip of South America.

Two case studies were presented. Case 1 was used to discuss the basic and principle features of the new cloud retrieval technique. This case study included an uncertainty discussion and comparisons with alternative approaches to derive cloud microphysical properties such as the singleFOV polarization lidar technique (Donovan et al., 2015) and a cloud-radar-based approach (Frisch et al., 2002). Good agreement was found.

Case 2 highlighted the new and extended potential of lidar to contribute to detailed ACI studies in the case of liquidwater clouds. Profiling of aerosol-relevant aerosol parameters close to the cloud base, cloud microphysical properties just above the cloud base, and vertical wind with $1 \mathrm{~min}$ resolution was possible and enabled a detailed updraft- and downdraft-resolved ACI study. For typical updraft conditions with vertical velocities $<50-70 \mathrm{~cm} \mathrm{~s}^{-1}$, we found $N_{\mathrm{d}}$ and $N_{\mathrm{CCN}}$ values (for $0.2 \%$ water supersaturation) ranging from $15-100 \mathrm{~cm}^{-3}$ and $75-200 \mathrm{~cm}^{-3}$, respectively, in the welldeveloped, preexisting stratocumulus deck at the top of the pristine marine boundary layer over Punta Arenas. ACI studies were performed separately for updraft and downdraft conditions with the particle extinction coefficient $\alpha_{\mathrm{par}}$ as well as with $N_{\mathrm{CCN}}$ as aerosol proxy. High ACI values of $0.8-1.0$ were found. The impact of aerosol water uptake on the ACI studies was illuminated with the result that the highest ACI values were obtained by considering the aerosol proxies $\alpha_{\text {par }}$ or $N_{\mathrm{CCN}}$ measured at heights about $500 \mathrm{~m}$ below the cloud base (and thus for dry aerosol conditions) in the ACI computations.

As an outlook, we will extend our ACI studies by means of the dual-FOV lidar method. We equipped three further Polly instruments with the dual-FOV polarization lidar technique. These lidars are or were operated at the North Pole (at $85-90^{\circ} \mathrm{N}$ ) on board the German ice breaker Polarstern from September 2019 to September 2020, at Dushanbe, Tajikistan, at polluted and dusty conditions in Central Asia since June 2019, and at Limassol, Cyprus, in the polluted and dusty eastern Mediterranean since October 2020. A fourth dualFOV Polly lidar will start long-term monitoring at Mindelo, Cabo Verde, in the outflow regime of pollution and dust from western and central Africa in 2021. A mobile dual-FOV Polly will be moved to New Zealand for further ACI studies in the Southern Ocean in 2021. All these field activities will be used to characterize $\mathrm{ACI}$ in the case of liquid-water clouds at very different aerosol and meteorological conditions.

We are presently analyzing the data of Punta Arenas and Dushanbe and are preparing a follow-up paper (tentative title: "Aerosol effects in liquid-water clouds: contrasting lidar ob- 
servations in dusty, polluted Central Asia and clean, southern South America"). Another goal is to initiate the further upgrading of the existing European lidar-radar network by implementing the dual-FOV lidar technique at several network supersites.

The integration of the dual-FOV-polarization lidar technique into the LACROS infrastructure can be regarded as the next systematic step to improve the capability of state-of-theart ground-based remote sensing towards an overall monitoring of aerosol-cloud interaction in liquid-water clouds as presented here and mixed-phase clouds and cirrus layers as presented recently by Bühl et al. (2019) and Ansmann et al. (2019)

Data availability. Polly lidar observations (level 0 data, measured signals) are in the PollyNET database (http://polly.rsd.tropos.de/; PollyNET, 2020). LACROS observations (level 0 data) are stored in the Cloudnet database of LACROS (http://lacros.rsd.tropos.de/; Cloudnet, 2020). All the analysis products are available at TROPOS upon request (info@tropos.de). Backward trajectory analysis has been supported by air mass transport computation with the NOAA (National Oceanic and Atmospheric Administration) HYSPLIT (HYbrid Single-Particle Lagrangian Integrated Trajectory) model (http://ready.arl.noaa.gov/HYSPLIT_traj.php; HYSPLIT, 2020). AERONET photometer observations of Punta Arenas are in the AERONET database (http://aeronet.gsfc.nasa.gov/; AERONET, 2020).

Author contributions. CJ and AA prepared the manuscript. CJ developed the new method and analyzed all field campaign observations. CJ, RE, and RW upgraded the Polly instrument. CJ, RE, PS, $\mathrm{MR}, \mathrm{BB}$, and JB took care of the DACAPO PESO campaign and the field campaign instrumentation. ZY determined the lidar calibration constants (for the aerosol retrieval below the cloud base). JB took care of the vertical wind retrievals. DD developed the code to analyze single-FOV polarization measurements. PS took care of the radar-based retrieval. DD, AM, PS, JS, and UW supported the discussion and interpretation of the observations.

Competing interests. The authors declare that they have no conflict of interest.

Special issue statement. This article is part of the special issue "EARLINET aerosol profiling: contributions to atmospheric and climate research". It is not associated with a conference.

Acknowledgements. The authors wish to thank TROPOS and UMAG for their logistic and infrastructural support during the preparation phase and during the DACAPO-PESO campaign at Punta Arenas. We are grateful to the technicians of the mechanical workshop of TROPOS for the always prompt and careful assistance when upgrading the Polly instruments. We thank AERONET for their continuous efforts in providing high-quality measurements and products. Aerosol source apportionment analysis has been supported by air mass transport computation with the rather convenient NOAA (National Oceanic and Atmospheric Administration) HYSPLIT (HYbrid Single-Particle Lagrangian Integrated Trajectory) model.

Financial support. This research has been supported by the DAAD/Becas Chile (grant no. 57144001) and the ACTRIS Research Infrastructure (EU H2020-R\&I) (grant no. 654109)

The publication of this article was funded by the Open Access Fund of the Leibniz Association.

Review statement. This paper was edited by Eduardo Landulfo and reviewed by three anonymous referees.

\section{References}

AERONET: Aerosol Robotic Network aerosol data base, available at: http://aeronet.gsfc.nasa.gov/, last access: 22 Februray 2020.

Ansmann, A., Mamouri, R.-E., Bühl, J., Seifert, P., Engelmann, R., Hofer, J., Nisantzi, A., Atkinson, J. D., Kanji, Z. A., Sierau, B., Vrekoussis, M., and Sciare, J.: Ice-nucleating particle versus ice crystal number concentrationin altocumulus and cirrus layers embedded in Saharan dust:a closure study, Atmos. Chem. Phys., 19, 15087-15115, https://doi.org/10.5194/acp-19-150872019, 2019.

Baars, H., Kanitz, T., Engelmann, R., Althausen, D., Heese, B., Komppula, M., Preißler, J., Tesche, M., Ansmann, A., Wandinger, U., Lim, J.-H., Ahn, J. Y., Stachlewska, I. S., Amiridis, V., Marinou, E., Seifert, P., Hofer, J., Skupin, A., Schneider, F., Bohlmann, S., Foth, A., Bley, S., Pfüller, A., Giannakaki, E., Lihavainen, H., Viisanen, Y., Hooda, R. K., Pereira, S. N., Bortoli, D., Wagner, F., Mattis, I., Janicka, L., Markowicz, K. M., Achtert, P., Artaxo, P., Pauliquevis, T., Souza, R. A. F., Sharma, V. P., van Zyl, P. G., Beukes, J. P., Sun, J., Rohwer, E. G., Deng, R., Mamouri, R.-E., and Zamorano, F.: An overview of the first decade of PollyNET: an emerging network of automated Raman-polarization lidars for continuous aerosol profiling, Atmos. Chem. Phys., 16, 5111-5137, https://doi.org/10.5194/acp16-5111-2016, 2016.

Baars, H., Seifert, P., Engelmann, R., and Wandinger, U.: Target categorization of aerosol and clouds by continuous multiwavelength-polarization lidar measurements, Atmos. Meas. Tech., 10, 3175-3201, https://doi.org/10.5194/amt-103175-2017, 2017.

Belegante, L., Bravo-Aranda, J. A., Freudenthaler, V., Nicolae, D., Nemuc, A., Ene, D., Alados-Arboledas, L., Amodeo, A., Pappalardo, G., D'Amico, G., Amato, F., Engelmann, R., Baars, H., Wandinger, U., Papayannis, A., Kokkalis, P., and Pereira, S. N.: Experimental techniques for the calibration of lidar depolarization channels in EARLINET, Atmos. Meas. Tech., 11, 11191141, https://doi.org/10.5194/amt-11-1119-2018, 2018.

Bühl, J., Seifert, P., Wandinger, U., Baars, H., Kanitz, T., Schmidt, J., Myagkov, A., Engelmann, R., Skupin, A., Heese, B., Kle- 
pel, A., Althausen, D., and Ansmann, A.: LACROS: the Leipzig Aerosol and Cloud Remote Observations System, Proc. SPIE, 8890, 889002, https://doi.org/10.1117/12.2030911, 2013.

Bühl, J., Seifert, P., Myagkov, A., and Ansmann, A.: Measuring ice- and liquid-water properties in mixed-phase cloud layers at the Leipzig Cloudnet station, Atmos. Chem. Phys., 16, 1060910620, https://doi.org/10.5194/acp-16-10609-2016, 2016.

Bühl, J., Seifert, P., Radenz, M., Baars, H., and Ansmann, A.: Ice crystal number concentration from lidar, cloud radar and radar wind profiler measurements, Atmos. Meas. Tech., 12, 66016617, https://doi.org/10.5194/amt-12-6601-2019, 2019.

Cloudnet: Cloudnet data base, available at: http://lacros.rsd.tropos. de/, last access: 20 April 2020.

Dai, G., Althausen, D., Hofer, J., Engelmann, R., Seifert, P., Bühl, J., Mamouri, R.-E., Wu, S., and Ansmann, A.: Calibration of Raman lidar water vapor profiles by means of AERONET photometer observations and GDAS meteorological data, Atmos. Meas. Tech., 11, 2735-2748, https://doi.org/10.5194/amt11-2735-2018, 2018.

Donovan, D., Voors, R., van Zadelhoff, G.-J., and Acarreta, J.-R.: ECSIM Model and Algorithms Document, KNMI Tech. Rep.: ECSIM-KNMI-TEC-MAD01-R, availanle at: https://www.academia.edu/33712449/ECSIM_Model_and_ Algorithms_Document (last access: 2 December 2020), 2010.

Donovan, D. P., Klein Baltink, H., Henzing, J. S., de Roode, S. R., and Siebesma, A. P.: A depolarisation lidar-based method for the determination of liquid-cloud microphysical properties, Atmos. Meas. Tech., 8, 237-266, https://doi.org/10.5194/amt-8237-2015, 2015.

Engelmann, R., Kanitz, T., Baars, H., Heese, B., Althausen, D., Skupin, A., Wandinger, U., Komppula, M., Stachlewska, I. S., Amiridis, V., Marinou, E., Mattis, I., Linné, H., and Ansmann, A.: The automated multiwavelength Raman polarization and water-vapor lidar PollyXT: the neXT generation, Atmos. Meas. Tech., 9, 1767-1784, https://doi.org/10.5194/amt-9-1767-2016, 2016.

Fossum, K. N., Ovadnevaite, J., Ceburnis, D., Preißler, J., Snider, J. R., Huang, R.-J., Zuend, A., and O'Dowd, C.: Sea-spray regulates sulfate cloud droplet activation over oceans, npj Clim. Atmos. Sci., 3, 14, https://doi.org/10.1038/s41612-020-0116-2, 2020.

Freudenthaler, V., Esselborn, M., Wiegner, M., Heese, B., Tesche, M., Ansmann, A., Müller, D., Althausen, D., Wirth, M., Fix, A., Ehret, G., Knippertz, P., Toledano, C., Gasteiger, J., Garhammer, M., and Seefeldner, M.: Depolarization ratio profiling at several wavelengths in pure Saharan dust during SAMUM 2006, Tellus B, 61, 165-179, https://doi.org/10.1111/j.16000889.2008.00396.x, 2009.

Freudenthaler, V.: About the effects of polarising optics on lidar signals and the $\Delta 90$ calibration, Atmos. Meas. Tech., 9, 41814255, https://doi.org/10.5194/amt-9-4181-2016, 2016.

Frisch, S., Shupe, M., Djalalova, I., Feingold, G., and Poellot, M.: The retrieval of stratus cloud droplet number effective radius with cloud radars, J. Atmos. Ocean. Tech., 19, 835-842, https://doi.org/10.1175/15200426(2002)019<0835:TROSCD>2.0.CO;2, 2002.

GDAS: Global Data Assimilation System, meteorological data base, available at: https://www.ready.noaa.gov/gdas1.php, last access: 20 March 2020.
Grosvenor, D. P., Sourdeval, O., Zuidema, P., Ackerman, A., Alexandrov, M. D., Bennartz, R., Boers, R., Cairns, B., Chiu, J. C., Christensen, M., Deneke, H., Diamond, M., Feingold, G., Fridlind, A., Hünerbein, A., Knist, C., Kollias, P., Marshak, A., McCoy, D., Merk, D., Painemal, D., Rausch, J., Rosenfeld, D., Russchenberg, H., Seifert, P., Sinclair, K., Stier, P., van Diedenhoven, B., Wendisch, M., Werner, F., Wood, R., Zhang, Z., and Quaas, J.: Remote sensing of droplet number concentration in warm clouds: A review of the current state of knowledge and perspectives, Rev. Geophys., 56, 409-453, https://doi.org/10.1029/2017RG000593, 2018.

Haarig, M., Ansmann, A., Gasteiger, J., Kandler, K., Althausen, D., Baars, H., Radenz, M., and Farrell, D. A.: Dry versus wet marine particle optical properties: RH dependence of depolarization ratio, backscatter, and extinction from multiwavelength lidar measurements during SALTRACE, Atmos. Chem. Phys., 17, 1419914217, https://doi.org/10.5194/acp-17-14199-2017, 2017.

Hofer, J., Althausen, D., Abdullaev, S. F., Makhmudov, A. N., Nazarov, B. I., Schettler, G., Engelmann, R., Baars, H., Fomba, K. W., Müller, K., Heinold, B., Kandler, K., and Ansmann, A.: Long-term profiling of mineral dust and pollution aerosol with multiwavelength polarization Raman lidar at the Central Asian site of Dushanbe, Tajikistan: case studies, Atmos. Chem. Phys., 17, 14559-14577, https://doi.org/10.5194/acp-17-145592017, 2017.

Hofer, J., Ansmann, A., Althausen, D., Engelmann, R., Baars, H., Abdullaev, S. F., and Makhmudov, A. N.: Long-term profiling of aerosol light extinction, particle mass, cloud condensation nuclei, and ice-nucleating particle concentration over Dushanbe, Tajikistan, in Central Asia, Atmos. Chem. Phys., 20, 4695-4711, https://doi.org/10.5194/acp-20-4695-2020, 2020.

Holben, B. N., Eck, T. F., Slutsker, I., Tanré, D., Buis, J. P., Setzer, A., Vermote, E., Reagan, J. A., Kaufman, Y. J., Nakajima, T., Lavenu, F., Jankowiak, I., and Smirnov, A.: AERONET - a federated instrument network and data archive for aerosol characterization, Remote Sens. Environ., 66, 1-16, 1998.

Hu, Y., Vaughan, M., Liu, Z., Lin, B., Yang, P., Flittner, D., Hunt, B., Kuehn, R., Huang, J., Wu, D., Rodier, S., Powell, K., Trepte, C., and Winker, D.: The depolarization - attenuated backscatter relation: CALIPSO lidar measurements vs. theory, Opt. Express 15, 5327-5332, 2007.

HYSPLIT: HYbrid Single-Particle Lagrangian Integrated Trajectory model, backward trajectory calculation tool, available at: http://ready.arl.noaa.gov/HYSPLIT_traj.php, last access: 20 February 2020.

Illingworth, A. J., Hogan, R. J., O’Connor, E. J., Bouniol, D., Delanoe, J, Pelon, J., Protat, A., Brooks, M. E., Gaussiat, N., Wilson, D. R., Donovan, D. P., Klein Baltink, H., van Zadelhoff, G.-J., Eastment, J. D., Goddard, J. W. F., Wrench, C. L., Haeffelin, M., Krasnov, O. A., Russchenberg, H. W. J., Piriou, J.-M., Vinit, F., Seifert, A., Tompkins, A. M., and Willen, J.: CLOUDNET: Continuos evaluation of cloud profiles in seven operational models using ground-based observations, B. Am. Meteorol. Soc., 88, 883-898, https://doi.org/10.1175/BAMS-88-6-883, 2007.

Jimenez, C., Ansmann, A., Donovan, D., Engelmann, R., Malinka, A., Schmidt, J., and Wandinger, U.: Retrieval of microphysical properties of liquid water clouds from atmospheric lidar measurements: Comparison of the Raman dual field of view 
and the depolarization techniques, Proc. SPIE, 10429, 1042907, https://doi.org/10.1117/12.2281806, 2017.

Jimenez, C., Ansmann, A., Donovan, D., Engelmann, R., Schmidt, J., and Wandinger, U.: Comparison between two lidar methods to retrieve microphysical properties of liquid water clouds, EPJ Web Conf., 176, 01032, https://doi.org/10.1051/epjconf/201817601032, 2018.

Liu, M., Lin, J., Boersma, K. F., Pinardi, G., Wang, Y., Chimot, J., Wagner, T., Xie, P., Eskes, H., Van Roozendael, M., Hendrick, F., Wang, P., Wang, T., Yan, Y., Chen, L., and Ni, R.: Improved aerosol correction for OMI tropospheric $\mathrm{NO}_{2}$ retrieval over East Asia: constraint from CALIOP aerosol vertical profile, Atmos. Meas. Tech., 12, 1-21, https://doi.org/10.5194/amt-12-1-2019, 2019.

Jimenez, C., Ansmann, A., Engelmann, R., Donovan, D., Malinka, A., Schmidt, J., Seifert, P., and Wandinger, U.: The dual-field-of-view polarization lidar technique: a new concept in monitoring aerosol effects in liquid-water clouds - theoretical framework, Atmos. Chem. Phys., 20, 15247-15263, https://doi.org/10.5194/acp-20-15247-2020, 2020.

Mamouri, R.-E. and Ansmann, A.: Potential of polarization lidar to provide profiles of $\mathrm{CCN}$ - and INP-relevant aerosol parameters, Atmos. Chem. Phys., 16, 5905-5931, https://doi.org/10.5194/acp-16-5905-2016, 2016.

Martin, G. M., Johnson, D. W., and Spice, A.: The measurement and parameterization of effective radius of droplets in warm stratocumulus clouds, J. Atmos. Sci., 51, 1823-1842, https://doi.org/10.1175/15200469(1994)051<1823:TMAPOE>2.0.CO;2, 1994.

Mattis, I., Tesche, M., Grein, M., Freudenthaler, V., and Müller, D.: Systematic error of lidar profiles caused by a polarization-dependent receiver transmission: quantification and error correction scheme, Appl. Optics, 48, 2741-2751, https://doi.org/10.1364/AO.48.002742, 2009.

McComiskey, A., Feingold, G., Frisch, A. S., Turner, D. D., Miller, M. A., Chiu, J. C., Min, Q., and Ogren, J. A.: An assessment of aerosol-cloud interactions in marine stratus clouds based on surface remote sensing, J. Geophys. Res., 114, D09203, https://doi.org/10.1029/2008JD011006, 2009.

Miles, N., Verlinde, J., Clothiaux, E.: Cloud droplet size distributions in low-level stratiform clouds, J. Atmos. Sci., 57, 295-311, 2000.

Painemal, D. and Zuidema, P.: The first aerosol indirect effect quantified through airborne remote sensing during VOCALS-REx, Atmos. Chem. Phys., 13, 917-931, https://doi.org/10.5194/acp13-917-2013, 2013.

Pappalardo, G., Amodeo, A., Apituley, A., Comeron, A., Freudenthaler, V., Linné, H., Ansmann, A., Bösenberg, J., D’Amico, G., Mattis, I., Mona, L., Wandinger, U., Amiridis, V., AladosArboledas, L., Nicolae, D., and Wiegner, M.: EARLINET: towards an advanced sustainable European aerosol lidar network, Atmos. Meas. Tech., 7, 2389-2409, https://doi.org/10.5194/amt7-2389-2014, 2014.

PollyNet: PollyNET lidar data base, available at: http://polly.rsd. tropos.de/, last access: 20 April 2020.

Regayre, L. A., Schmale, J., Johnson, J. S., Tatzelt, C., Baccarini, A., Henning, S., Yoshioka, M., Stratmann, F., GyselBeer, M., Grosvenor, D. P., and Carslaw, K. S.: The value of remote marine aerosol measurements for constraining radia- tive forcing uncertainty, Atmos. Chem. Phys., 20, 10063-10072, https://doi.org/10.5194/acp-20-10063-2020, 2020.

Reutter, P., Su, H., Trentmann, J., Simmel, M., Rose, D., Gunthe, S. S., Wernli, H., Andreae, M. O., and Pöschl, U.: Aerosol- and updraft-limited regimes of cloud droplet formation: influence of particle number, size and hygroscopicity on the activation of cloud condensation nuclei (CCN), Atmos. Chem. Phys., 9, 70677080, https://doi.org/10.5194/acp-9-7067-2009, 2009.

Revell, L. E., Kremser, S., Hartery, S., Harvey, M., Mulcahy, J. P., Williams, J., Morgenstern, O., McDonald, A. J., Varma, V., Bird, L., and Schuddeboom, A.: The sensitivity of Southern Ocean aerosols and cloud microphysics to sea spray and sulfate aerosol production in the HadGEM3-GA7.1 chemistry-climate model, Atmos. Chem. Phys., 19, 1544715466, https://doi.org/10.5194/acp-19-15447-2019, 2019.

Rolph, G., Stein, A., and Stunder, B.: Real-time Environmental Applications and Display sYstem: READY, Environ. Modell. Softw., 95, 210-228, https://doi.org/10.1016/j.envsoft.2017.06.025, 2017.

Schmale, J., Baccarini, A., Thurnherr, I., Henning, S., Efraim, A., Regayre, L., Bolas, C., Hartmann, M., Welti, A., Lehtipalo, K., Aemisegger, F., Tatzelt, C., Landwehr, S., Modini, R. L., Tummon, F., Johnson, J. S., Harris, N., Schnaiter,M., Toffoli, A., Derkani, M., Bukowiecki, N., Stratmann, F., Dommen, J., Baltensperger, U., Wernli, H., Rosenfeld, D., Gysel-Beer, M. and Carslaw, K. S.: Overview of the Antarctic Circumnavigation Expedition: Study of Preindustrial-like Aerosols and Their Climate Effects (ACE-SPACE), B. Am. Meteorol. Soc., 100, 2260-2283, https://doi.org/10.1175/BAMS-D-18-0187.1, 2019

Schmidt, J., Wandinger, U., and Malinka, A.: Dual-fieldof-view Raman lidar measurements for the retrieval of cloud microphysical properties, Appl. Optics 52, 2235-2247, https://doi.org/10.1364/AO.52.002235, 2013.

Schmidt, J., Ansmann, A., Bühl, J., Baars, H., Wandinger, U., Müller, D., and Malinka, A. V.: Dual-FOV Raman and Doppler lidar studies of aerosol-cloud interactions: simultaneous profiling of aerosols, warm-cloud properties, and vertical wind, J. Geophys. Res., 119, 5512-5527, https://doi.org/10.1002/2013JD020424, 2014.

Schmidt, J., Ansmann, A., Bühl, J., and Wandinger, U.: Strong aerosol-cloud interaction in altocumulus during updraft periods: lidar observations over central Europe, Atmos. Chem. Phys., 15, 10687-10700, https://doi.org/10.5194/acp-15-106872015, 2015.

Shinozuka, Y., Clarke, A. D., Nenes, A., Jefferson, A., Wood, R., McNaughton, C. S., Ström, J., Tunved, P., Redemann, J., Thornhill, K. L., Moore, R. H., Lathem, T. L., Lin, J. J., and Yoon, Y. J.: The relationship between cloud condensation nuclei $(\mathrm{CCN})$ concentration and light extinction of dried particles: indications of underlying aerosol processes and implications for satellitebased CCN estimates, Atmos. Chem. Phys., 15, 7585-7604, https://doi.org/10.5194/acp-15-7585-2015, 2015.

Skupin, A., Ansmann, A., Engelmann, R., Seifert, P., and Müller, T.: Four-year long-path monitoring of ambient aerosol extinction at a central European urban site: dependence on relative humidity, Atmos. Chem. Phys., 16, 1863-1876, https://doi.org/10.5194/acp-16-1863-2016, 2016. 
Stein, A. F., Draxler, R. R, Rolph, G. D., Stunder, B. J. B., Cohen, M. D., and Ngan, F.: NOAA's HYSPLIT atmospheric transport and dispersion modeling system, B. Am. Meteorol. Soc., 96, 2059-2077, https://doi.org/10.1175/BAMS-D-14$00110.1,2015$
Zheng, X., Albrecht, B., Jonsson, H. H., Khelif, D., Feingold, G., Minnis, P., Ayers, K., Chuang, P., Donaher, S., Rossiter, D., Ghate, V., Ruiz-Plancarte, J., and Sun-Mack, S.: Observations of the boundary layer, cloud, and aerosol variability in the southeast Pacific near-coastal marine stratocumulus during VOCALS-REx, Atmos. Chem. Phys., 11, 9943-9959, https://doi.org/10.5194/acp-11-9943-2011, 2011. 